\title{
Unemployment Insurance with Endogenous Search Intensity and Precautionary Saving ${ }^{1,2}$
}

\author{
James S. Costain \\ Universitat Pompeu Fabra
}

November 1997

Correspondence address:

Department of Economics and Business

Universitat Pompeu Fabra

Ramon Trias Fargas 25-27

08005 Barcelona Spain

costain@upf.es

\footnotetext{
${ }^{1}$ I would like to thank my dissertation chair Michael Woodford, and my committee members Steven Davis and Lars Hansen, for their advice, support, and patience with this project. I am also indebted to Dale Mortensen, James Heckman, Thomas Sargent, Fernando Avalos, Daron Acemoglu, Randall Wright, and many supportive friends and helpful seminar participants. All errors, of course, are my own.

${ }^{2}$ This paper comprises the core sections of my dissertation, Costain (Aug. 1997).
} 


\section{Abstract}

A welfare analysis of unemployment insurance (UI) is performed in a general equilibrium job search model. Finitely-lived, risk-averse workers smooth consumption over time by accumulating assets, choose search effort when unemployed, and suffer disutility from work. Firms hire workers, purchase capital, and pay taxes to finance worker benefits; their equity is the asset accumulated by workers. A matching function relates unemployment, hiring expenditure, and search effort to the formation of jobs. The model is calibrated to US data; the parameters relating job search effort to the probability of job finding are chosen to match microeconomic studies of unemployment spells.

Under logarithmic utility, numerical simulation shows rather small welfare gains from UI. Even without UI, workers smooth consumption effectively through asset accumulation. Greater risk aversion leads to substantially larger welfare gains from UI; however, even in this case much of its welfare impact is due not to consumption smoothing effects, but rather to decreased work disutility, or to a variety of externalities.

JEL classification: J65, J64, J22, E21

Keywords: Unemployment insurance, matching, search effort, moral hazard, precautionary saving, prudence, life cycle 


\section{Introduction}

This paper provides a quantitative analysis of the costs and benefits of unemployment insurance (UI). While the welfare implications of UI are an important public policy concern, the equilibrium economic modeling of the effects of UI is still in its preliminary stages. Most previous studies of the issue have looked in detail only at the costs of UI, or only at the benefits of UI, because of the difficulty of specifying a complete model that treats both sides of the welfare analysis endogenously. There are three main strands to the previous literature. General equilibrium search models, with linear utility, such as Millard and Mortensen (1994), have examined the costs of UI in terms of the hiring disincentives it creates. Moral hazard models, such as Hopenhayn and Nicolini (1994), have looked at the costs of UI in terms of the disincentive to job search that it imposes upon workers. Precautionary savings models, such as Hubbard, Skinner, and Zeldes (1995), have studied the consumption smoothing benefits of various social insurance schemes. The goal of this paper is to combine aspects of these three literatures to provide a framework for an overall welfare analysis of UI.

After a literature review, we present the model which we will use to perform a numerical welfare analysis in section 2. In our model, finitely-lived workers choose between consumption and saving, and also choose search effort when unemployed. They have constant relative risk aversion utility of consumption, and receive disutility from search effort and work effort. Firms hire workers, purchase capital, and must pay taxes to finance worker benefits; their equity is the asset accumulated by workers. A matching function relates unemployment, hiring expenditure, and search effort to the formation of jobs. In this context, UI may benefit workers by helping them smooth their consumption, but it also raises unemployment through its impact on the incentives of workers and firms. A welfare calculation must furthermore consider the disutility of search and work, and will be affected by the presence of external effects in search and in capital accumulation. 
Section 3 parameterizes the model to fit the relevant features of the U.S. economy. Production and matching technology are calibrated from aggregate share parameters and from previous studies of aggregate matching. The disutility of work can be identified from the wage bargaining equation. The parameters relating job search effort to the probability of job finding are chosen to match stylized facts from microeconomic studies of the unemployment spells of workers eligible for UI.

The results of the numerical simulation, which appear in the fourth section of the paper, mostly fail to show great potential for welfare gains from UI on the basis of consumption smoothing. In our more risk averse simulations, relatively large consumption smoothing benefits are sometimes observed, but with logarithmic utility only the average level of consumption appears to be significant for workers' well-being. Other less obvious considerations also play an important role in the net welfare outcome; much of the gain from UI is found to come from decreases in the disutility of work, and a variety of externalities are important in some of our calculations. The minor scope for consumption smoothing in our model is attributable to the high degree of self-insurance occurring in equilibrium. However, we also consider evidence that our model, which includes no heterogeneity of worker types, may overstate equilibrium self-insurance and thus understate the benefits of UI.

One of the main contributions of this paper is that it adds the effects of endogenous search intensity to a general equilibrium UI framework, whereas previous papers have focused on the tradeoff between consumption smoothing and tax distortions on hiring. Thus it treats what may well be the primary concern expressed about UI programs, and in doing so it unifies the theoretical approaches to UI based on search, precautionary savings, and moral hazard. The primary difficulty in solving our main numerical model- besides computer time- is not the theoretical apparatus needed to include endogenous search intensity, but rather finding an appropriate parameterization. Hence we make a second contribution by showing, in the third section, how the parameters of unobservable search intensity can be identified from the effects of policy experiments on labor market outcomes. The third reason this study should 
be of interest is simply that the framework employed can be judged against a considerable number of empirical implications; overall, we can reproduce many aspects of the economy quite successfully with the model used here.

\subsection{Relation to the literature}

A large empirical literature exists on the tendency of UI to increase unemployment. Meyer (1990) nonparametrically estimates job finding rates and shows significant negative effects of the replacement ratio (the ratio of the UI benefit to the wage) on job finding. He also demonstrates that job finding increases as a worker's time of UI eligibility runs out; he finds a clear spike in job finding at the end of eligibility. Feldstein (1978) and Anderson and Meyer (1994) measure the role of imperfectly experience rated UI as a subsidy to temporary layoffs. A number of papers analyze policy changes and controlled experiments, such as Meyer (1995), who reviews experimental policies that involved paying a bonus to those who found jobs quickly, and Solon (1985), who studies the effect of imposing income taxes on UI benefits. Papers attempting to quantify the benefits of UI include Dynarski and Sheffrin (1987), Hamermesh and Slesnick (1995), and Gruber (1994). Gruber finds significant drops in consumption due to unemployment, and finds that higher replacement ratios cushion this drop. Ehrenberg and Oaxaca (1976) ask whether UI also leads to the eventual acceptance of higher-wage jobs, but do not find this effect.

This paper does not analyze empirical data, but instead constructs a numerical model which will be calibrated for consistency with some of the empirical studies listed above. As mentioned earlier, three main frameworks have been used to construct previous UI models - the theories of job search, moral hazard, and precautionary savings. We now discuss each of these types of models in turn, with reference to previous studies of UI and their relation to the present model.

Theoretical analyses of the costs of UI are based on the presumption that increasing UI benefits will raise unemployment. Probably the most widely accepted way of endogenizing unemployment is the job search framework, as 
discussed in Mortensen (1986) and Pissarides (1990), which explicitly takes into account the time costs or other costs involved in finding work opportunities. The levels of vacancies and unemployment - or more generally, the levels of recruitment activity by firms and job search activity by workers - are assumed to determine the rate at which new job matches are formed in the economy. From an individual's point of view, then, the time required to find a job is an exponential random variable, and from an economy-wide perspective, there is always some fraction of the workforce which is unemployed, that is, which is waiting for job opportunities.

General equilibrium search models, such as Pissarides (1987) and Mortensen and Pissarides (1994), shed light on a number of macroeconomic issues such as the business cycle dynamics of unemployment and vacancies. Andolfatto (1996) shows how labor market search can help explain business cycle patterns of productivity correlation. These models can also be used to study how unemployment will be affected by labor market policies like UI. Millard and Mortensen (1994) analyze the impact of UI replacement ratios and benefit eligibility durations on the US and UK unemployment rates. Sargent and Ljungqvist (1995) use a partial equilibrium model to show that UI can lead to high, persistent unemployment if human capital depreciates during unemployment. A recent empirical treatment of search theory is Yashiv (1997), who uses generalized method of moments estimation to fit both firm and worker matching behavior in the Israeli economy.

These general equilibrium matching papers focus primarily on firms' willingness to hire workers, given the government's labor market policies. However, UI also affects the unemployment rate through workers' incentives to find jobs. Note that if workers' search activity were entirely observable, this would not be a concern; the provider of UI could simply require the worker to undertake an appropriate level of job finding activity as a condition of benefit payment. In fact, U.S. workers are required to demonstrate that they are engaged in job search in order to receive UI payments. ${ }^{1}$ Nonetheless the literature makes the

\footnotetext{
${ }^{1}$ There is evidence that these requirements are at least partially effective; cutting back requirements to report job search activity caused large increases in unemployment spell length in an experiment described in Meyer (1995).
} 
reasonable assumption that this requirement is not entirely effective. Instead, a moral hazard problem exists; raising UI will decrease worker search incentives, and given the imperfect ability to monitor search activity, search and job finding will decrease. Note also that moral hazard models necessarily include a cost of working or searching, which must be taken into account in a welfare analysis; in fact, we will find these costs to be quantitatively important for our evaluation of UI.

Rather like the early partial equilibrium search papers, the moral hazard model of Hansen and Imrohoroglu (1992) features an economy in which workers choose whether to accept randomly arriving job offers. Workers in their equilibrium prefer to remain unemployed rather than working, as long as they retain their unemployment benefits; also, they lose their benefits with probability less than one even if they turn down an offer, which means that they are less willing to accept jobs as UI is increased. An alternative formulation of moral hazard is adopted here, as in Hopenhayn and Nicolini (1994) and Chapter 4 of Pissarides (1990). In the equilibrium of this paper, a worker always prefers to accept a job once she finds one, but the probability of finding a job is a function of the effort devoted by the worker to job search, and this effort has a disutility cost. At the aggregate level, the rate at which new job matches are formed will be a function of firms' hiring activity, the number of unemployed workers, and also the search effort of the unemployed. Because we will assume search activity cannot be observed, search effort will fall, and unemployment will rise, when an increase in UI lowers the net benefits of finding a job.

Paradoxically, most of the literature studying the effects of UI on unemployment is incapable of addressing the intended benefits of UI, because utility has usually been assumed linear, for the sake of analytical tractability. ${ }^{2}$ There is no reason to provide insurance in an economy of consumers with linear utility, since such consumers care only about the expected present discounted value of income, not about its time path or variability. With concave utility, however, smoother consumption matters; transfer of income from states in

\footnotetext{
${ }^{2}$ Hansen and Imrohoroglu (1992) are an exception to this rule.
} 
which a consumer is well off to states in which she is poor improve her lifetime utility even if they have no effect on the expected present value of her income. UI may provide a way of smoothing consumption, both by insuring the level of income, and, if there are liquidity constraints, by allowing individuals to consume more than their income in early periods if necessary.

Even with concave utility, however, the scope for benefits from UI may be limited by the availability of other methods for smoothing consumption, such as precautionary saving. The precautionary saving literature therefore examines the effectiveness of self-insurance through asset accumulation. Kimball (1990) discusses the role of a positive third derivative of utility in such precautionary saving behavior, a restriction satisfied by the constant relative risk aversion utility function that appears in our calculations. Carroll (1992) and Deaton $(1991,1992)$ also contain extensive discussions of precautionary saving and related behavior based on liquidity constraints. A number of authors have also studied the response of precautionary savings and consumption variability to the provision of various types of social welfare or insurance benefits. Engen and Gruber (1995) evaluate the effects of UI on asset holdings. Hubbard, Skinner, and Zeldes (1995) show that means-tested social benefit programs can help account for the fact that many of the poor have very low asset levels. Rendon (1996) studies empirical and theoretical relations between asset holding, unemployment, and wages.

The main difficulty that has discouraged previous use of concave utility in search models of unemployment is that the precautionary saving it implies will cause individuals to accumulate different amounts of wealth depending on their luck in the labor market. ${ }^{3}$ Workers who have accumulated larger quantities of assets are both richer and more effectively insured, and hence behave differently from those with fewer assets. To describe the overall state of the economy, then, and to predict aggregate behavior, it is necessary to know the entire distribution of assets across agents. For standard utility functions, such as

\footnotetext{
${ }^{3}$ With linear utility, since the time path of consumption is irrelevant for behavior, we can without loss of generality assume that all income is consumed immediately. Thus workers remain effectively identical regardless of their past labor market histories.
} 
constant relative risk aversion, even partial equilibrium precautionary savings models like Zeldes (1989) require a numerical, rather than analytical solution. In general equilibrium the numerical solution must be performed repeatedly, for each new candidate price vector, as one searches for an equilibrium.

Combining these considerations with search models creates further difficulties, for in search models, standard competitive price-taking arguments do not apply. Wages are instead assumed to be set by bargaining; several specifications of the bargaining problem have been considered in Binmore, Rubinstein, and Wolinsky (1982) and in Wolinsky (1987). The bargaining incentives will in general depend on asset holdings, and thus wage outcomes should vary across individuals according to asset holdings, a fact which is unfortunately usually ignored in macroeconomic models.

A number of authors have attempted to combine general equilibrium UI models with concave utility. An early paper is the two-period model of Baily (1978). Hansen and Imrohoroglu (1992) allow for precautionary savings in a model with an exogenous probability of receiving a job offer. More recently, Valdivia (1995) numerically solves a general equilibrium job search model of UI with precautionary savings and fixed search intensity. Costain (1995) finds an analytical solution for the distribution of assets in a more stylized model of search and precautionary savings, for the special case of exponential utility and fixed search intensity. In both these papers, however, the lack of endogenous search activity is a major drawback. Both assume variation in job formation comes only from firms' hiring incentives, not from workers' choice of job search effort - and thus are unable to address one of the most important potential problems arising from a UI policy.

The difficulty of adding endogenous search to a numerical UI model is not theoretical. It involves defining an additional choice variable, and thus is somewhat computationally burdensome, but the real problem lies in the fact that workers' search effort is unobserved, so that there is little direct evidence to guide the choice of the parameters relating search activity to disutility and to job finding probabilities. However, we will show in some detail in this paper how, for a reasonable choice of functional form, the relevant parameters can 
be identified from evidence on the effects of UI policy on unemployment spell durations.

Finally, we should note that general equilibrium UI models are now an active area of research involving several other authors. Papers include Alvarez and Veracierto (1996), Zhang (1996), Judd and Solnick (1995), Albrecht and Vroman (1997), and Acemoglu and Shimer (1997).

\section{The model and algorithm}

We begin with a summary of the model which we will use to compare the costs and benefits of UI. The UI program we will consider pays benefits over the first two periods of any unemployment spell, cutting off payments thereafter. It is financed by a tax on firms, levied on the basis of a fixed payment per employee. Our policy analysis will examine how steady state average utility changes as the level of UI benefits paid is altered.

Since we wish to model the benefits of an insurance program, we choose a utility function such that workers display risk aversion in consumption. The constant relative risk aversion utility function we use also implies prudence, which means that workers will engage in precautionary saving; this potential for self-insurance may reduce the scope for welfare improvements from UI. As discussed above, this precautionary asset accumulation also complicates the solution of the model by requiring us to calculate a distribution of asset holdings across individuals. Workers live for a fixed number of periods, and for the sake of realism in our asset distribution we assume that they are retired over the last periods of their lives, during which time they receive a fixed social security payment.

To study the effects of UI on the unemployment rate, we endogenize the probability of unemployment by means of a general equilibrium search model. The rate of match formation in our economy is a function of the amount of hiring activity by firms, the number of unemployed workers, and the search effort of unemployed workers. 
Firms' incentives to hire workers will be affected by a UI program because the taxes used to finance UI will make labor more costly. Furthermore, since expenditure on hiring is a form of investment, undertaken in expectation of future returns, firms' willingness to hire will be a decreasing function of the interest rate. Taxes and interest rates will similarly affect capital purchases by firms. The interest rate will be determined in general equilibrium by workers' demand for assets and the supply of assets in the form of (riskless) firm equity.

UI will also drive up the unemployment rate by decreasing the cost, to workers, of being unemployed. Workers are assumed to experience a fixed level of disutility from work effort when employed, and a variable level of disutility from their choice of search effort when unemployed. A higher choice of search effort implies a higher probability of job finding; the moral hazard problem in our model arises from our assumption that search is unenforceable because it cannot be observed. We will ignore the possibility of quitting a job to collect UI benefits, which amounts to assuming that quits can be distinguished from layoffs. Note finally that our overall welfare conclusions about UI must account not only for its effects on utility from consumption, but also for its impact on the disutility expended on search and work.

\subsection{The worker's problem}

For computational reasons, the worker's situation will be described as a discrete time, discrete choice problem. However, this is intended as an approximation to a continuous problem featuring a worker with the instantaneous utility function

$$
\frac{1}{\alpha} c^{\alpha}-D^{S} s-D^{W} \mathbf{1}_{\{\epsilon=1\}}
$$

over consumption $c$ and search effort $s$. Here $\alpha \leq 1, D^{S} \geq 0, D^{W} \geq 0$, and $\mathbf{1}_{\{\epsilon=1\}}$ is an index function which equals one when the individual is employed and zero otherwise. The individual has a finite, deterministic lifetime, with a working life of $T$ periods followed by $T^{R}$ periods of retirement, and utility discount rate $\rho>0$. The transition from employment to unemployment arrives with fixed probability $\delta$ per unit of time; the transition back to employment 
occurs with variable probability $\pi s^{Z}$ per unit of time. The worker faces wage $w$, unemployment benefit $b^{U}$, social security benefit $b^{R}$, and interest rate $r$. Unemployment benefits are paid for the first two periods of any unemployment spell.

For the discrete model used in this paper, assume that an individual's lifetime utility function is defined over an integer number of time steps $T+T^{R}$; in the first $T$ steps, the worker is in the labor force, while during the last $T^{R}$ steps, she is retired. A new generation of $I /\left(T+T^{R}\right)$ workers is born at each integer time, so that the total population at any moment is $I$. We will write $I^{W} \equiv I T /\left(T+T^{R}\right)$ for the number of individuals of working age. The generation which works in periods $t$ to $t+T-1$ and is retired in periods $t+T$ to $t+T+T^{R}-1$ will be called generation $t$.

A worker chooses a rate of consumption at each point in her life; during periods of unemployment in her working life, she also chooses a level of search intensity. We require that consumption $c$, the search effort $s$, and beginning-ofperiod asset holdings $a$ (prior to that period's labor income and expenditures) each be an element of an appropriate finite set:

$$
\begin{gathered}
c \in \mathcal{C} \equiv\left\{0, \chi, 2 \chi, \ldots, c_{\max }\right\} \\
s \in \mathcal{S} \equiv\left\{0, \exp \left(\sigma_{\min }\right), \exp \left(\sigma_{\min }+\sigma\right), \ldots, \exp \left(\sigma_{\max }\right)\right\} \\
a \in \mathcal{A} \equiv\left\{-a_{\min },-a_{\min }+\chi, \ldots, 0, \ldots, a_{\max }-\chi, a_{\max }\right\}
\end{gathered}
$$

where $\chi, \sigma, \sigma_{\min }, \sigma_{\max }, c_{\max }, a_{\min }$, and $a_{\max }$ are all positive constants. ${ }^{4,5}$ Likewise, the worker's employment state $\epsilon$ takes one of five discrete values. We write $\epsilon=1$ if the worker is employed. The first and second periods of an unemployment spell are given by $\epsilon=2$ and $\epsilon=3$, respectively; $\epsilon=4$ refers to the third and later periods of an unemployment spell, when the worker is ineligible for UI. Finally, $\epsilon=5$ means that the worker has retired.

\footnotetext{
${ }^{4}$ In the last period of life the worker consumes all her remaining endowment, which need not be an integral multiple of $\chi$.

${ }^{5}$ We make use of the constant step size of consumption $\chi$ in speeding up calculation; by contrast, there is no computational disadvantage in allowing exponential levels of $s$.
} 
Since we will only consider the economy in an aggregate steady state, it suffices to write policy functions without mention of aggregate variables. Consumption and search can be written as $c_{g}(a, \epsilon, t)$ and $s_{g}(a, \epsilon, t)$ for a member of generation $g$ at time $g \leq t<g+T+T^{R}$ with beginning-of-period assets $a$ and employment status $\epsilon$. Consumption behavior $c_{g}(., .,$.$) will determine the$ worker's transition from one level of assets to another, given income. Sources of income are the wage $w$, the unemployment benefit $b^{U}$, and the social security benefit $b^{R}$, as well as interest income earned at rate $r$ on asset holdings. End-of-period asset holdings are thus

$$
\tilde{a}_{g}(a, \epsilon, t)=a+w \mathbf{1}_{\{\epsilon=1\}}+b^{U} \mathbf{1}_{\{\epsilon=2 \vee \epsilon=3\}}+b^{R} \mathbf{1}_{\{\epsilon=5\}}-c_{g}(a, \epsilon, t)
$$

and expected assets next period are $R \tilde{a}$, where $R \equiv \exp (r)$. We make small, random adjustments to the asset accumulation process to ensure that assets remain constrained to the grid set $\mathcal{A} .{ }^{6}$

Search behavior $s_{g}(., . .$.$) affects the transition between the unemployed$ and employed states during the first $T$ periods of life. Job loss will be treated exogenously; a currently employed person of age $T-1$ or less becomes unemployed in the next period with probability $1-\exp (-\delta)$, and otherwise remains employed. An unemployed person of age $T-1$ or less becomes employed in the next period with probability $1-\exp \left(-\pi s^{Z}\right)$ if she chooses search intensity $s$; otherwise she remains unemployed. Here $Z \in[0,1]$ is an exogenous constant; $\pi$ is an endogenous coefficient which is related in equilibrium to the unemployment rate and the level of recruitment by firms. ${ }^{7}$

\footnotetext{
${ }^{6}$ Suppose assets at the end of period $t$ are $\tilde{a}_{t}$, so that expected asset holdings at the beginning of period $t+1$ are $R \tilde{a}_{t}$, Define $\left(R \tilde{a}_{t}\right)^{-}$and $\left(R \tilde{a}_{t}\right)^{+}$to be the elements of set $\mathcal{A}$ which bound $R \tilde{a}_{t}$ from below and from above, respectively. We require that realized asset holdings $a_{t+1}$ at the start of period $t+1$ take the following values:

$$
a_{t+1}=\left\{\begin{array}{lll}
\left(R \tilde{a}_{t}\right)^{-} & \text {with probability } & \chi^{-1}\left(\left(R \tilde{a}_{t}\right)^{+}-R \tilde{a}_{t}\right) \\
\left(R \tilde{a}_{t}\right)^{+} & \text {with probability } & \chi^{-1}\left(R \tilde{a}_{t}-\left(R \tilde{a}_{t}\right)^{-}\right)
\end{array}\right.
$$

${ }^{7}$ Instead of the Poisson arrival rate $\pi s^{Z}$ per unit time assumed in the continuous time problem, we specify the job finding probability as $1-\exp \left(-\pi s^{Z}\right)$ to ensure that the probability of finding a job within a quarter is bounded between zero and one. We ignore the possibility of multiple job offers in the discrete time interval.
} 
Table 1: The worker's problem

$\operatorname{Max}$
$c_{0}(., .,.) \in \mathcal{C}$
$s_{0}(., .,.) \in \mathcal{S}$$\quad E_{0} \sum_{0 \leq t<T+T^{R}} e^{-\rho t}\left[\frac{1}{\alpha}\left(c_{0}\left(a_{t}, \epsilon_{t}, t\right)+\underline{\chi}\right)^{\alpha}-D^{S} s_{0}\left(a_{t}, \epsilon_{t}, t\right)-D^{W} \mathbf{1}_{\{\epsilon=1\}}\right]$

subject to the asset transition equations:

$$
\begin{gathered}
c_{0}\left(a_{t}, \epsilon_{t}, t\right)+\tilde{a}_{t}=a_{t}+w \mathbf{1}_{\{\epsilon=1\}}+b^{U} \mathbf{1}_{\{\epsilon=2 \vee \epsilon=3\}}+b^{R} \mathbf{1}_{\{\epsilon=5\}} \quad \forall a_{t}, \epsilon_{t}, t \\
\text { and } a_{t+1}=\left\{\begin{array}{l}
\left(R \tilde{a}_{t}\right)^{-} \text {with prob. } \chi^{-1}\left(\left(R \tilde{a}_{t}\right)^{+}-R \tilde{a}_{t}\right) \\
\left(R \tilde{a}_{t}\right)^{+} \text {with prob. } \chi^{-1}\left(R \tilde{a}_{t}-\left(R \tilde{a}_{t}\right)^{-}\right)
\end{array}\right. \\
\text {where } a_{0}=0 \text { and } a_{T+T^{R}} \geq 0 \text { for all histories. }
\end{gathered}
$$

Also subject to the employment transition equations:

$$
\operatorname{pr}\left(\epsilon_{0}=1\right)=p_{0} ; \quad \epsilon_{t}=5 \text { for } t \geq T
$$

and for $t \in\{0,1,2, \ldots, T-2\}$ :

probability of unemployment at $t+1$ if employed at $t$

$$
=1-\exp (-\delta)
$$

probability of employment at $t+1$ if unemployed at $t$

$$
=1-\exp \left(-\pi s_{0}\left(a_{t}, \epsilon_{t}, t\right)^{Z}\right)
$$


The complete statement of the problem of a worker of generation 0 is given in Table 1 . The tiny constant $\underline{\chi}$ is added to consumption to ensure that utility is finite even when consumption is zero. Note that welfare comparisons under extremely low levels of UI are somewhat suspect, as they are sensitive to the value of $\underline{\chi}$; therefore in this paper we will instead focus on utility comparisons between different non-trivial levels of UI. The variable $p_{o}$ is the probability of beginning life employed; although perhaps unrealistic, it is convenient in our framework to allow this to be a positive number. ${ }^{8}$

\subsection{The firm's problem}

Firms act in the interest of their shareholders by maximizing the present value of profits. They hire labor and purchase capital, and the net revenue above their costs is paid out as dividends to shareholders. Like workers, firms are active in a discrete set of times, but unlike workers, firms are infinitely lived, and they face no uncertainty. That is, we assume that firms are sufficiently large relative to workers that they can exploit the law of large numbers and treat the probabilistic arrival of individual workers as a continuous, deterministic process. In an aggregate steady state, the firm's problem depends only on its individual state variables, which are its stocks of capital and employees, $k_{t}$ and $n_{t}$. The firm's production function for gross output is $A n_{t}{ }^{\gamma} k_{t}^{1-\gamma}$.

Firms adjust their stocks of capital and labor by expenditure on investment $i_{t}$ and hiring $h_{t}$. Hiring leads to the arrival of new employees at rate $q_{t} h_{t}$, where $q_{t}$ is an endogenous coefficient related in equilibrium to the search and hiring effort of all workers and firms. The fraction of capital which remains after one period's depreciation is $\exp \left(-\delta_{k}\right)$, and likewise the fraction of workers who are still employed at the firm after a period is $\exp (-\delta)$.

In choosing hiring, the firm takes as given a wage $w_{t}$; we will discuss the derivation of this endogenous variable below. It must also pay a tax $\tau_{t}$ per

\footnotetext{
${ }^{8}$ As we will see below, we allow the jobs of retiring workers to be inherited by newly born workers so that the firm always faces a probability $\exp (-\delta)$ that a given match will continue; we thus avoid the necessity that the firm take into account the age distribution of its workers in choosing its hiring policy.
} 
employee which is used to finance UI and social security benefits. Hence we can state the firm's problem in terms of its value function $V\left(n_{t}, k_{t}\right)$ as:

$$
\begin{gathered}
V\left(n_{t}, k_{t}\right)=\operatorname{Max}_{h_{t}, i_{t}}\left\{A n_{t}^{\gamma} k_{t}^{1-\gamma}-w_{t} n_{t}-\tau_{t} n_{t}-h_{t}-i_{t}+\frac{1}{R_{t}} V\left(n_{t+1}, k_{t+1}\right)\right\} \\
\text { s.t. } n_{t+1}=q_{t} h_{t}+\exp (-\delta) n_{t} \\
\text { and } k_{t+1}=i_{t}+\exp \left(-\delta_{k}\right) k_{t}
\end{gathered}
$$

This problem yields the following pair of Euler equations:

$$
\begin{gathered}
R_{t}-\exp \left(-\delta_{k}\right)=A(1-\gamma) n_{t}{ }^{\gamma} k_{t}{ }^{-\gamma} \\
R_{t}-\exp (-\delta)=q_{t}\left(A \gamma n_{t}{ }^{\gamma-1} k_{t}{ }^{1-\gamma}-w_{t}-\tau_{t}\right)
\end{gathered}
$$

This formulation of the problem embodies constant returns to scale, both in production and in the hiring and investment processes, an assumption which is common in the general equilibrium matching literature. Given this assumption, the number and size of firms is indeterminate; we can think of economic activity taking place in one large firm or in many of different sizes. All, however, will choose the same capital to labor ratio. The determinacy of the capital to labor ratio, and the indeterminacy of the size of the firm, can both be seen from the necessary conditions (1)-(2), in which labor and capital enter only as a ratio, never independently. ${ }^{9}$

\subsection{Wage determination.}

Since this is a search model, where the formation of a match requires a prior expenditure of time and effort, there is a non-trivial gain in welfare, called the match surplus, accruing to a worker and a firm when they become matched. In simple competitive models of labor markets, a worker or firm can walk away from any given wage offer to immediately find the market wage, which implies

\footnotetext{
${ }^{9}$ The constant returns to scale assumption makes this economy equivalent to one in which "firms" consist only of a single vacancy each. For a demonstration of the equivalence of the one-on-one matching framework with a world of constant returns to scale firms, see Pissarides (1990), Ch. 2.
} 
that there is no gain associated with being currently matched and that both sides of the relation are forced to act as price takers. By contrast, in a search model, the surplus must be divided on the basis of bilateral bargaining. In this paper, we will impose a model of bargaining which is justified on the basis of an extensive form alternating offers game by Wolinsky (1987), who shows that it is the most appropriate bargaining solution for a search model with endogenous search intensity. ${ }^{10}$

The wage bargaining solution to be employed here is most easily explained in a period-by-period context. The surplus for a given period is defined to be the difference in the sum of the payoffs of the worker and the firm depending on whether or not work occurs that period; that is, the threat points of the worker and the firm are those associated with a strike. ${ }^{11}$ The wage is derived by assuming that fixed fractions of this surplus accrue to the worker and the firm, which also arises as a subgame perfect equilibrium of an alternating offers game played at the start of each period to determine that period's wage.

If work occurs, the marginal product $A \gamma(k / n)^{1-\gamma}$ is produced, and the worker experiences disutility $D^{W} /\left(c^{\alpha-1}\right)$, where we have deflated by the worker's current marginal utility of consumption to express the disutility in units comparable to the output of the firm. We will assume that the firm's tax bill is unaffected by a strike; hence the tax rate does not enter into the calculation of the surplus associated with work relative to a strike. The worker's gain from

\footnotetext{
${ }^{10}$ A bargaining solution of this type was first used by Shaked and Sutton (1984).

${ }^{11}$ The more common bargaining solution imposed in the search literature defines the surplus intertemporally as the difference in the sum of the value functions of the worker and the firm between the matched and unmatched states; that is, the threat points are those associated with separation. As shown by Wolinsky (1987), such a solution cannot be derived as a subgame perfect equilibrium of an alternating offers game when search intensity is endogenous. The intuition behind the result is that it is never a credible threat to separate from a match with positive surplus, unless one has already obtained an offer to enter into an alternative match. Moreover, it is also not a credible threat to incur the disutility costs of searching for such an alternative match when, on the equilibrium path, both parties expect an acceptable wage offer to be made immediately. Costain (1996) also discusses this result, and shows that it can arise either from a single alternating offers game played at the beginning of the match, or from playing a new alternating offers game at the start of each period.
} 
working is her pay minus her disutility. Thus, if the worker's bargaining share is $\beta$, Nash bargaining implies:

$$
w_{t}-D^{W} c_{t}^{1-\alpha}=\beta\left(A \gamma n_{t}^{\gamma-1} k_{t}^{1-\gamma}-D^{W} c_{t}^{1-\alpha}\right)
$$

Equivalently, we obtain the simple wage equation:

$$
w_{t}=\beta A \gamma n_{t}^{\gamma-1} k_{t}^{1-\gamma}+(1-\beta) D^{W} c_{t}^{1-\alpha}
$$

which shows that the wage is a weighted average of the marginal product of labor and the disutility of work.

This wage is taken as given in the decision problems of the worker and the firm. In equilibrium, strikes do not occur, even though it is the possibility of a strike that determines this wage. Unfortunately, note that this bargaining solution should in fact be a function of the asset holdings of the worker, since chosen consumption, and hence marginal utility, will vary with assets. Like Valdivia (1995), we will simplify the model by calculating the wage from (4) relative to average consumption in the economy. In Costain (Nov. 1997), several simple variations on our wage bargaining solution are explored, and apparently subtle specification changes are shown to have a major impact on the equilibrium.

\subsection{Aggregate consistency conditions}

Aggregate consistency between our descriptions of the problems of the worker and the firm imposes some additional necessary conditions on our equilibium. First, we require that the government follow a balanced budget at all times, equating total taxes to expenditure on UI and social security:

$$
n_{t} \tau_{t}=I^{W} u_{t}^{U I} b^{U}+\left(I-I^{W}\right) b^{R}
$$

for all $t$. The variable $u_{t}^{U I}$ represents the fraction of workers who are currently in the first or second period of an unemployment spell, and who are thus eligible for UI benefits. ${ }^{12}$

\footnotetext{
${ }^{12}$ Since the number of firms is indeterminate, we are using $n_{t}$ here to refer to the total number of workers employed in the economy, as opposed to the number at a specific firm; we will use $k_{t}, h_{t}$, and $i_{t}$ similarly below.
} 
To state market clearing conditions for this economy, we need to define a distribution function for the number of workers $\phi_{g}(a, \epsilon, t)$ from generation $g$ with asset holdings $a$ and employment status $\epsilon$ at time $t$. We normalize the distribution so that the frequencies sum to the total number of workers: ${ }^{13}$

$$
\sum_{a, \epsilon, g} \phi_{g}(a, \epsilon, t)=I
$$

Using this notation, the goods market clearing condition can be written as follows:

$$
A n_{t}{ }^{\gamma} k_{t}{ }^{1-\gamma}-i_{t}-h_{t}=\sum_{a, \epsilon, g} c_{g}(a, \epsilon, t) \phi_{g}(a, \epsilon, t)
$$

for all $t$ and in the steady state.

In writing the firm's problem, we have treated capital goods as assets held by the firms, not by individuals. The natural asset to be held by individuals, then, is the equity of the firms. In steady state, asset market consistency requires that the total interest earnings by workers on end-of-period asset holdings equal total dividend payments $d_{t}$ by firms. We can write this as

$$
(R-1) \sum_{a, \epsilon, g} \tilde{a}_{g}(a, \epsilon, t) \phi_{g}(a, \epsilon, t)=d=A n^{\gamma} k^{1-\gamma}-w n-\tau n-h-i
$$

Since there are no capital gains in steady state, requiring consistency of dividend earnings in this way also suffices for consistency of stocks of assets held in our economy.

The relevant rates of unemployment in our economy can be defined as

$$
u_{t}^{U I}=\sum_{a, \epsilon, g} \mathbf{1}_{\epsilon \in\{2,3\}} \phi_{g}(a, \epsilon, t)
$$

and

$$
u_{t}^{T O T}=\sum_{a, \epsilon, g} \mathbf{1}_{\epsilon \in\{2,3,4\}} \phi_{g}(a, \epsilon, t)
$$

Equality of labor market stocks requires that

$$
I^{W}\left(1-u_{t}^{T O T}\right)=n_{t}
$$

\footnotetext{
${ }^{13}$ The summation is over $a \in \mathcal{A}, \epsilon \in\{1,2,3,4,5\}$, and over the set of $g$ alive at $t$, but we suppress this notation.
} 
Imposing consistency of separation flows is almost trivial since both workers and firms are assumed to become separated with the same constant probability $(1-\exp (-\delta))$. The only complication is that we must assume that fraction $\exp (-\delta)$ of the jobs held by retiring workers are inherited by newborn workers in the next period; this ensures that firms need not consider the age distribution of their workforce in choosing hiring and investment.

We also wish to ensure consistency of matching flows, and to ensure an overall rate of matching which is an increasing, concave function of firms' hiring activity, as well as of the number of unemployed and of their search activity. We can achieve such a specification by defining the matching coefficients as follows:

$$
\begin{gathered}
\pi_{t} \equiv \mu h_{t}^{\xi}\left(I^{W} u_{t}^{T O T}\right)^{-\xi} \\
q_{t} \equiv \frac{1}{h_{t}} \sum_{a, \epsilon, g} \phi_{g}(a, \epsilon, t)\left(1-\exp \left(-\pi_{t} s_{g}(a, \epsilon, t)^{Z}\right)\right)
\end{gathered}
$$

We assume that the exogenous parameters here satisfy $\mu>0$ and $\xi \in(0,1)$. With these definitions, we have total matches formed per period equal to

$$
q_{t} h_{t}=\sum_{a, \epsilon, g} \phi_{g}(a, \epsilon, t)\left(1-\exp \left(-\pi_{t} s_{g}(a, \epsilon, t)^{Z}\right)\right)=(1-\exp (-\delta)) n
$$

where the last equation holds only in steady state. For this matching function, if all workers pick the same level of search effort $\bar{s}$, and if $\pi \bar{s}^{Z}$ is small, then we have:

$$
\sum_{a, \epsilon, g} \phi_{g}(a, \epsilon, t)\left(1-\exp \left(-\pi_{t} s_{g}(a, \epsilon, t)^{Z}\right)\right) \approx \mu h^{\xi}\left(I^{W} u^{T O T}\right)^{1-\xi} \bar{s}_{t}^{Z}
$$

This approximation shows that the matching function has roughly constant returns to scale in hiring and unemployment, and is also an increasing, concave function of workers' search activity. 


\subsection{Solution algorithm}

Because of our choice of a constant relative risk aversion utility function, the model under consideration has no analytical solution. In fact, calculating an equilibrium of our economy necessarily implies finding a fixed point of the dynamics of the distribution of assets and employment across workers of all ages. Since a distribution is a high-dimensional object, this is in general very difficult, both in terms of calculating the dynamics and in terms of verifying convergence. However, we now show that identifying a steady state equilibrium of this economy can be reduced to a fixed point problem in three numbers: the interest factor $R$, the matching rate coefficient $\pi$, and the wage $w$. Table 2 outlines the algorithm used.

We calculate an equilibrium under the assumption that the government has exogenously specified benefit levels $b^{U}$ and $b^{R}$. The calculation begins by guessing preliminary values for $R, \pi$, and $w$. These five numbers are all we need to solve the individual's problem by dynamic programming, working backwards from the last period of life, in which all remaining assets are consumed. The policy function at each age defines probabilities of transition from each state $(a, \epsilon)$ at age $t$ to possible states at time $t+1$. We can use these transition probability matrices to calculate the overall distribution $\phi_{g}(a, \epsilon, t)$ of assets and employment by age. ${ }^{14}$

Given the solution to the worker's problem, we can calculate the labor market variables $u^{U I}, u^{T O T}$, and $n$, from equations (9), (10), and (11). Average consumption is

$$
\bar{c}=\sum_{a, \epsilon, g} \phi_{g}(a, \epsilon, t) c_{g}(a, \epsilon, t)
$$

The government's budget constraint determines the tax rate $\tau$ that is required to finance the chosen benefit level:

$$
\tau=\left(I^{w} u^{U I} b^{U}+\left(I-I^{w}\right) b^{R}\right) / n
$$

\footnotetext{
${ }^{14}$ Note that the sequence of transition matrices from age 1 to age 2 , age 2 to age 3 , etc., can be multiplied to define longer horizon transition matrices from age 1 to any older age. It is the eigenvector (with eigenvalue one) of the transition matrix from birth to retirement that is used to calculate the probability $p_{0}$ of being born employed.
} 
Table 2: The algorithm

0. Pick policy parameters $b^{U}, b^{R}$.

1. Make initial guesses of $R, \pi$, and $w$.

2. Given $R, \pi, w, b^{U}$, and $b^{R}$, solve the individual's problem by backwards induction.

3. From the worker's policy functions, calculate the steady state distribution of asset holdings and employment status by age.

4. From workers' steady state behavior, calculate $n, u^{T O T}, u^{U I}, \tau$, and average consumption $\bar{c}$.

5. Use the firm's Euler equations and laws of motion (16)-(19), to calculate $k$, $q, h$, and $i$.

6. Calculate new values for $R, \pi$, and $w$ from equations (20), (21), and (22).

7. If guessed and predicted values of $R, \pi$, and $w$ are sufficiently close, equilibrium has been found. If not, return to step 2 . 
We can now calculate the implications of the firm's problem. The following four equations are steady state versions of the Euler equations and the laws of motion for labor and capital:

$$
\begin{aligned}
R-\exp (-\delta) & =A(1-\gamma)(n / k)^{\gamma} \\
R-\exp \left(-\delta_{k}\right) & =q\left(A \gamma(k / n)^{1-\gamma}-w-\tau\right) \\
q h & =n(1-\exp (-\delta)) \\
i & =k\left(1-\exp \left(-\delta_{k}\right)\right)
\end{aligned}
$$

Since we already know $R$ and $n$, equation (16) gives us $k$. (17) then determines $q$, while the last two equations determine $h$ and $i$.

Finally we have sufficient information to check whether we have reached an equilibrium by calculating new values for $R, \pi$, and $w$ :

$$
\begin{gathered}
R=1+\frac{\left(A n^{\gamma} k^{1-\gamma}-w n-\tau n-i-h\right)}{\sum_{a, \epsilon, g} \tilde{a}_{g}(a, \epsilon, t) \phi_{g}(a, \epsilon, t)} \\
\pi=\mu h^{\xi}\left(I^{W} u^{T O T}\right)^{-\xi} \\
w=\beta A \gamma(k / n)^{1-\gamma}+(1-\beta) D^{W}(\bar{c}+\bar{\chi})^{1-\alpha}
\end{gathered}
$$

These three equations merely repeat the asset market clearing condition (8), the definition of $\pi$ (12), and the wage equation (4). A fixed point of the three equations (20)-(22) is a steady state equilibrium of the economy. Twenty to thirty iterations of the loop stated in Table 2 typically suffice, depending on the accuracy of the initial guess; Newton's method is used to speed final convergence. The entire process takes two to six hours on the workstation employed. Note that the simulations reported below are typically accurate to four to five significant figures. The degree of accuracy achieved suffices for clear welfare calculations. 


\section{Parameterization}

Some of the parameters that are crucial to this numerical exercise are not standard in the macroeconomic literature, so we will discuss the parameterization in detail. A few parameter choices correspond to arbitrary normalizations; some others can be observed directly. We then go on to discuss how the parameters of the production function can be approximately identified by trying to match aggregate observable variables.

Next we will consider various parameters of the matching function and the utility function. The parameters $\alpha, \rho$, and $\beta$ will all be given conventional values, which will allow us to use the wage equation (4) to fit the disutility of work $D^{W}$. We choose the matching elasticity $\xi$ on the basis of previous aggregate empirical work, and we determine $\mu$ by normalizing the units of search intensity. Finally, the most challenging aspect of the parameterization is the identification of $D^{S}$ and $Z$, which are level and elasticity parameters relating workers' unobserved search intensity to matching probabilities. We will show that the results of well-known experiments regarding the response of workers' rates of job finding to changes in UI policy can shed light on these parameters. While the identification is not very precise, we find that small changes in these parameters do not greatly alter our equilibrium. However, we also perform a sensitivity analysis with respect to risk aversion which shows that the value of $\alpha$ is critical for our conclusions.

We should be cautious about such a model, which simplifies the economy by allowing for only a single representative type of worker. This strategy implies arbitrariness in some of our parameter choices; for example, though different types of workers have very different rates of job loss, we pick a single constant rate. Likewise, though different types of individuals have very different wealth accumulation patterns in the US, we treat all capital as wealth held by workers for life cycle or precautionary saving purposes. 


\subsection{Normalizations and directly observable parameters}

Without loss of generality, we state all quantities in per capita terms and thus define $I \equiv 1 . .^{15}$ We are also free to specify the goods unit; while this normalization does not nail down one specific parameter, we will pick the technological parameters below in such a way as to achieve a level of aggregate value added (approximately) equal to one. As a third normalization, we set the time unit equal to a quarter, choosing $T \equiv 180$ and $T^{R} \equiv 60$, which corresponds to 45 years of working life from age 21 to age 65 , followed by 15 years of retirement and death at age 80 . This is somewhat longer than US life expectancy, and thus might seem to overstate retirement savings incentives, but is probably reasonable since we are ignoring other causes of saving, such as uncertainty about length of life as well as bequest incentives.

We will choose a value of $\delta_{k} \equiv 0.025$ for the capital depreciation rate, or approximately $10 \%$ per annum, which is a standard calibration in macroeconomic models. In considering the job separation rate $\delta$, however, we must confront the fact that our model of ex ante homogeneous workers is intended to represent the very heterogeneous U.S. economy. Measurements of monthly transition probabilities from unemployment to employment, for white males in the US, include 0.0086 in Marston (1976) and 0.015 in Ehrenberg and Smith (1994). Roughly on the basis of these numbers, we pick $\delta \equiv 0.04$ at quarterly rates. However, the flow rates for the young and for non-whites are substantially higher. ${ }^{16}$ Such diversity makes it impossible to calibrate a model to the job loss and job finding rates of the median US worker and still obtain an unemployment rate as high as that in the the US. Using our job loss rate of

\footnotetext{
${ }^{15}$ Table 5 describes the discretization, as well as other parameters. The minimum step size for consumption and assets is $1 / 12$, roughly one twelfth of quarterly per capita value added, given our normalization of the goods unit. The dynamic programming problem considers 425 levels of assets, 41 levels of consumption, and 17 levels of search intensity. The minimum level of asset holdings is a debt of roughly two quarters' average income; this imposes a binding, and probably realistic, borrowing constraint in equilibrium on a small fraction of young workers.

${ }^{16}$ Note also that we are ignoring the fact that a large fraction of labor market transitions are to and from a third state, "out of the labor force".
} 
0.04 (rather high for the median worker) we will find, in our baseline calculations below, an average job finding rate of roughly $50 \%$ per quarter. Valdivia (1995), on the other hand, chooses a job loss rate of 0.015 per quarter and thus, to obtain an unemployment rate comparable to that in the US, chooses a much lower job finding rate of 0.21 (rather low for the typical US worker.) Either calibration represents a reasonable compromise, since neither model allows for multiple types of workers. ${ }^{17}$

\subsection{Aggregate identification of technology}

We proceed to show that the parameters of the production function, $A$ and $\gamma$, can be identified by attempting to match a number of aggregate variables, if we also choose a normalization of the goods variable. Our normalization of the goods unit is chosen so that in equilibrium, value added is approximately equal to one. The aggregate equilibrium quantities that we will target include the following: an interest rate of $1.5 \%$ per quarter, an investment rate $i=$ 0.2 , unemployment at $u=0.06$, and labor's share of income equal to 0.65 . Matching these targets will imply that the capital stock is

$$
k=i /(1-\exp (-\delta))=8.1
$$

quarters of value added. ${ }^{18}$

The employment level is

$$
I^{W}\left(1-u^{T O T}\right)=0.705
$$

We impose unemployment and social security benefits of 0.33 , in the goods unit of the model. This implies a tax rate of

$$
\tau=\left(I^{W} u^{U I} b^{U}+\left(1-I^{W}\right) b^{R}\right) / n=0.138
$$

\footnotetext{
${ }^{17}$ Note that, for a given equilibrium $u$, the calibration used here, which is more nearly i.i.d. due to its quicker transitions, will be more amenable to self insurance than that of Valdivia; it will also have more of its unemployed eligible for UI, since individuals are more likely to find a job before benefits run out.

${ }^{18}$ This is somewhat low relative to US data, but we will see later that a low estimate of capital is helpful to reconcile the firm's side of the model with the individual's side.
} 
per worker, assuming that $u^{U I}$ and $u^{T O T}$ are similar. Since these tax payments should be classified as non-wage benefits, they should be included in labor's share. Hence we have

$$
(w+\tau) / \text { value added }=\text { labor's share }
$$

and our implied target value for the wage is

$$
w=(\text { labor's share)(value added) } / n-\tau=0.784
$$

The replacement ratio, and similarly the ratio of social security benefits to the wage, is then $0.33 / 0.784=0.421$. This is reasonable, since Engen and Gruber (1995) calculate the replacement ratio at $44 \%$.

A less commonly considered quantity is the fraction of output spent on hiring. One estimate is that of Barron, Black, and Lowenstein (1989), ${ }^{19}$ who estimate that approximately one month of labor time (partly time of the hiree, and partly time of pre-existing employees) is spent on a typical hire, including basic job training, in a mostly low-wage sample. If we assume that a typical job lasts five years (roughly consistent with our $\delta$ ) then this implies that $1 / 60$ of the duration of a typical job is devoted to hiring activities. Valuing labor time in accordance with the labor share mentioned above, this means that approximately $1 \%$ of GDP is spent on recruitment activity. We will therefore set a target level of $h=0.01$ for this model. ${ }^{20}$

The preceding information on the values of $\delta, \delta_{k}, n, k, h, R, w$, and $\tau$ now allows us to use the implications of the firm's problem, together with our normalization of the goods unit, to calculate the parameters $A$ and $\gamma$ that characterize the production function. The first equation below normalizes the goods unit; the second and third are the Euler equations from the firm's problem, as stated previously in (1) and (2).

$$
A n^{\gamma} k^{1-\gamma}-h=1
$$

\footnotetext{
${ }^{19}$ As summarized in Ehrenberg and Smith (1994).

${ }^{20}$ Nickell (1986) gives roughly similar estimates of the time costs of hiring, but emphasizes the great heterogeneity which exists across worker types. Note also that it is also unclear how much, if any, of job training expenditure should be included in the role of a hiring cost.
} 


$$
\begin{gathered}
R-\exp (-\delta)=\frac{(1-\exp (-\delta))}{h}\left[A \gamma\left(\frac{k}{n}\right)^{1-\gamma}-w-\tau\right] \\
R-\exp \left(-\delta_{k}\right)=A(1-\gamma)\left(\frac{n}{k}\right)^{\gamma}
\end{gathered}
$$

Clearly, with three equations and two unknowns, the system is overidentified, so we will not be able to find $A$ and $\gamma$ that fit the equations exactly. Instead, we minimize the sum of squared differences between the left- and right-hand sides of these equations, and find optimal technology parameters of $A \equiv 0.63$ and $\gamma \equiv 0.67$ approximately. ${ }^{21}$ The value of $\gamma$ found is clearly consistent with other studies which, in a competitive equilibrium framework, simply equate labor's share to the elasticity of output with respect to the labor input. $^{22}$

Note that our parameterization has relied on assumptions about the values of some general equilibrium variables, such as the interest rate. Since the production function parameters we have identified will not yield the desired firm behavior unless our assumptions about the general equilibrium variables are correct, we now briefly consider whether asset demand is likely to match supply at the assumed interest rate. In our model, the supply of assets is the total value of firms, which can be shown to equal

$$
a=\frac{h}{1-\exp (-\delta)}+\frac{i}{1-\exp \left(-\delta_{k}\right)}=\frac{n}{q}+k
$$

With our parameterization, we have $k=8.1, n=0.705$, and $q=3.1$, so total asset supply is $a=8.33$. To approximate asset demand by individuals, assume

\footnotetext{
${ }^{21}$ The second and third equations were scaled up by a factor of 10 to ensure that percentage deviations in all three equations would carry roughly equal weight.

${ }^{22}$ We can also check the consistency of the three equations by calculating the capital to labor ratio they will imply under our target interest factor $R=1.015$. From equation (25), we have:

$$
\frac{k}{n}=\left(\frac{A(1-\gamma)}{R-\exp \left(-\delta_{k}\right)}\right)^{1 / \gamma}=12.02
$$

which is close to our target value of 11.49. The parameterization is also fairly consistent in terms of its implications for the marginal product of labor, which is 0.941 if the capital to labor ratio is 11.49 , versus 0.955 if the capital to labor ratio is 12.02 .
} 
that the utility discount rate $\rho$ is equal to the interest rate $r=0.015$, and that $u^{U I}=u^{T O T} \equiv u$. Assume there is no uncertainty, so that workers consume a constant amount, and that workers have income $y^{W} \equiv w(1-u)+b^{U} u$ during their working lives and income $b^{R}=b^{U}$ during retirement. It can then be shown that the value of peak assets will be

$$
\frac{\left(w-b^{U}\right)(1-u)}{r}\left[\frac{1-e^{-r T^{R}}}{e^{r T}-e^{-r T^{R}}}\right]\left(e^{r T}-1\right)=21.1
$$

in units of quarterly per capita value added. Average assets will be

$$
\frac{\left(w-b^{U}\right)(1-u)}{r\left(T+T^{R}\right)}\left[\frac{1}{e^{r T}-e^{-r T^{R}}}\right]\left[\left(e^{r T}-1\right) T^{R}-\left(1-e^{-r T^{R}}\right) T\right]=7.76
$$

Actual asset holdings in our model will be somewhat higher, since this approximation ignores the precautionary motive; hence it appears that asset supply and demand should be consistent at $r=0.015 .^{23}$

\subsection{Search technology and utility}

We are now ready to take a closer look at preferences and search parameters. Since we are targetting an interest rate of $1.5 \%$, we will set the discount rate at $\rho \equiv 0.015$. We will set the risk aversion parameter at $\alpha \equiv 0$, implying logarithmic utility, though we will also report sensitivity analyses as this parameter is both important and controversial. For the bargaining share parameter, we choose the natural baseline $\beta \equiv 0.5$, implying equal bargaining power between the firm and the worker. These three parameters now suffice to determine the level of work disutility implied by the wage. By rearranging the wage equation (4), we derive: ${ }^{24}$

$D^{W}=\frac{c^{\alpha-1}}{1-\beta}\left(w-\beta A \gamma n^{\gamma-1} k^{1-\gamma}\right)=\frac{0.8^{-1}}{0.5}(0.784-0.5 * 0.941)=0.78$

\footnotetext{
${ }^{23}$ See Table 10 below for comparable observations on US asset holdings.

${ }^{24}$ As stated previously, we are using economy-wide average consumption to compute marginal utility.
} 
This wage equation can be seen to imply a tight relationship between the parameterization of $\alpha$ and that of $D^{W}$; when we perform sensitivity analyses with respect to $\alpha$ below, we will vary $D^{W}$ too in order to ensure a reasonable equilibrium wage.

We choose the matching elasticity $\xi$ for consistency with Blanchard and Diamond's (1989) study of the relation between unemployment, recruitment, and match formation. They regress aggregate matching rates on unemployment and on vacancies, as proxied by help-wanted advertising, and find elasticity estimates of roughly 0.45 and 0.55 , respectively, failing to reject constant returns to scale. We assume vacancies created by firms are directly proportional to firms' hiring expenditure, which means that our exponent $\xi$ on $h$ corresponds to their exponent of 0.55 on vacancies. ${ }^{25}$ On the worker's side, the exponent $1-\xi$ on $u$ corresponds to Blanchard and Diamond's elasticity of 0.45 only if unobserved search activity $z$ is uncorrelated with $u$. We will assume this is the case, on the grounds that a recession, when $u$ is high, both increases search activity by making people feel poorer and decreases it since a higher $u$ implies that search is less effective.

We can fit one more matching parameter by noting that the units of search effort can be arbitrarily rescaled. The scale of the unit of search effort affects $s$, $\pi, \mu$, and $D^{S}$, but no other variables; nailing down the value of any one of these quantities determines the scale of the others. We will choose a normalization which sets the equilibrium level of search effort $s$ roughly, but not exactly, equal to one (of course, $s$ varies across individuals in equilibrium.) In steady state, total matches must equal total job loss:

$$
I^{W}\left(1-u^{T O T}\right)(1-\exp (-\delta))=\sum_{a, \epsilon, g} \phi_{g}(a, \epsilon, t)\left[1-\exp \left(-\pi s_{g}(a, \epsilon, g)^{Z}\right)\right]
$$

\footnotetext{
${ }^{25}$ Yashiv (1997) regresses aggregate matches on measures of unemployment and vacancies from Israeli employment agency data and obtains results consistent with those of Blanchard and Diamond. However, he also fits the firm's problem by GMM and finds that vacancies are not directly proportional to hiring expenditure; instead, the total cost of hiring is a very convex function of the number of vacancies created. Interestingly, this calls into question all standard general equilibrium matching models which, like this paper, assume constant returns to scale in production and a constant cost of vacancy creation. Unfortunately we cannot pursue this observation further here.
} 


$$
\approx I^{W} u^{T O T}\left[1-\exp \left(-\pi \bar{s}^{Z}\right)\right]
$$

where $\bar{s}$ is the average level of $s$. If $\bar{s}=1$, this would imply that

$$
\pi=-\log \left(1-\frac{\left(1-u^{T O T}\right)(1-\exp (-\delta))}{u^{T O T}}\right)=0.95
$$

when $u^{T O T}=0.06$; hence this will be our target level for equilibrium $\pi$. Then, from equation (12), $\mu$ must be given by

$$
\mu=\pi\left(\frac{I^{W} u^{T O T}}{h}\right)^{\xi}=2.2
$$

This is our calibration of $\mu$, which fixes the units of $s, \pi$, and $D^{S}$.

\subsection{Identifying the impact of search effort}

The two search disutility parameters which remain to be identified are critical for the model; $D^{S}$ determines the cost of search and is thus related to the level of unemployment in equilibrium, while the elasticity $Z$ will govern how strongly unemployment responds to changed labor market policies. We now discuss several types of empirical observations that can help us identify these parameters. First, we wish to achieve an unemployment rate of roughly $6 \%$. Second, we review the results of a variety of studies showing how job finding rates vary with the UI replacement ratio and with a worker's remaining duration of UI benefits. Third, we note that $Z$ and $D^{S}$ may also have implications for other observables in our model, such as the response of consumption to job loss. We will try to match all these implications of the model by appropriate choice of $Z$ and $D^{S}$.

One study which sheds light on the difficulty of job finding is Meyer (1990), who looks at changes in job finding as UI benefits expire. In a sample of US workers from 1978 to 1983, Meyer shows that there is a 50\% chance of job finding in the second-to-last quarter of UI eligibility. This probability rises to $61 \%$ in the last quarter of eligibility, and to a quarterly rate of $69 \%$ over the 
last six weeks of eligibility. ${ }^{26}$ We are inclined to accept the higher rate of $69 \%$ as a better estimate of the change in individual job finding rates, since the actual rise in job finding probability may be masked by a selection effect, as those least likely to find a job are a larger part of the sample at longer spell lengths.

Solon (1985) documents changes in unemployment spells resulting from the imposition of UI benefits on high-wage workers in 1978, prior to which all benefits had been untaxed. The workers in this sample faced a replacement ratio of somewhat under $50 \%$, and the tax rate to which they were exposed by the new policy was around $22 \%-30 \%$, so that the replacement ratio effectively fell by $0.25^{*} 0.5=12.5$ percentage points. Solon estimates that this led to a 1.2 week decline in the length of the average UI-eligible spell ${ }^{27}$ for such workers, about $1 / 10$ of their initial value, which was roughly one quarter. A fall in spell lengths by a factor of $1 / 10$ corresponds to a fall in the unemployment rate by the same factor, that is, by 0.006 if unemployment is 0.06 . This translates into a drop in unemployment by 0.0005 for each drop of 0.01 in the replacement ratio. $^{28}$

In another paper, Meyer (1995) documents the results of a series of policy experiments in various U.S. states in the mid-1980s in which UI claimants were paid a cash bonus for finding jobs quickly. Typically, $\$ 500$ was paid for job finding within the first quarter of unemployment; such a payment tended to decrease spell lengths by half a week or by one week. With our quarterly model, the effects of this payment should closely resemble those of the UI benefit level, since both involve a second-quarter payment that affects search in the first period. In our model, the first period's UI benefit does not

\footnotetext{
${ }^{26}$ These figures are calculated from the weekly job finding rates reported in Table IV of Meyer (1990).

${ }^{27}$ In a more tentative calculation, he also estimates that total spells fell by two weeks.

${ }^{28}$ Note that it is somewhat unclear whether this should be interpreted as a general equilibrium or partial equilibrium change: the reforms in question affected a large minority of workers, and the samples of spells that Solon studies before and after the policy change are separated by about a year.
} 
directly affect search behavior, while the second period of UI lowers first period search; similarly, a bonus payment raises first period search by an amount which should have the same dollar-for-dollar impact as the (second period) UI benefit level. ${ }^{29}$ For comparability to Solon, note that $\$ 500$ in 1985 dollars is worth $\$ 320$ in 1978 dollars, or about $\$ 320 / \$ 2500=0.13$ of quarterly income in Solon's context. The drop in spell lengths is roughly 1/20 of a quarter- that is, roughly $1 / 20$ of the average spell length - and thus should imply a drop in the unemployment rate by $0.05^{*} 0.06=0.003$. Assuming that this is perfectly comparable to a change in the replacement ratio, this means that a change of 0.01 in the replacement ratio should lead to a change in the unemployment rate of $0.003 / 13=0.00023$, about half the effect we estimated from Solon's paper.

In Tables 3 and 4, we illustrate the approximate range of $Z$ and $D^{S}$ values that best match these empirical observations. The level parameter $D^{S}$ is tied down quite closely, at around 0.15 or 0.2 . The elasticity parameter is less well identified, yielding broadly similar results when it is around two times $D^{S}$, in a range from 0.2 to 0.6 .

Table 3 shows the impact of the parameter $D^{S}$. Raising $D^{S}$ makes search more costly, and thus when $D^{S}$ is at 0.3 or above, $u$ quickly rises to levels substantially higher than those we are aiming for. The effect of lowering $D^{S}$ is somewhat more paradoxical. We would probably expect a lower $D^{S}$ simply to decrease the rate of unemployment. Instead, we find that the rate of secondquarter unemployment rises substantially, while post-UI unemployment falls. The explanation is that low utility costs of search make it very easy to find a job during the second period of unemployment. The incentive to search in the first period of unemployment, when another period of UI is still assured, is thus diminished; instead, many agents search very little in the first period, making

\footnotetext{
${ }^{29}$ More accurately, this argument overstates the comparability of the results of the two papers. Since actual search decisions are made continually, rather than at a quarterly frequency, first-quarter UI benefits will also impact search behavior, so that a dollar change in the bonus experiment is not really equally effective as a dollar change in the UI benefit level. This helps explain why the apparent effect of monetary incentives in Meyer's context is smaller than that we calculate from Solon's paper.
} 
Table 3: Effects of $D^{S}$ when $Z=0.4$.

$\begin{array}{lccc}\text { Std dev of consumption } & 0.0695 & 0.0723 & 0.0746 \\ \text { Avg U/E cons ratio } & 0.9492 & 0.9508 & 0.9483 \\ \text { Cert eq of cons/avg cons } & 0.9956 & 0.9958 & 0.9951 \\ \text { Cons innov due to job loss } & -2.81 \% & -3.50 \% & -3.43 \% \\ \text { Total unemployment } & 0.0731 & 0.0763 & 0.0787 \\ \text { 1st qtr unemp } & 0.0363 & 0.0362 & 0.0361 \\ \text { 2nd qtr unemp } & 0.0236 & 0.0229 & 0.0228 \\ \text { Post-UI unemp } & 0.0132 & 0.0173 & 0.0196 \\ \text { 1st qtr prob of job finding } & 0.3571 & 0.3664 & 0.3698 \\ \text { 2nd qtr prob of job finding } & 0.6384 & 0.5650 & 0.5312 \\ \text { Post-UI prob of job finding } & 0.6472 & 0.5762 & 0.5438 \\ \text { Change in u from raised UI } & 0.0043 & 0.0025 & 0.0021 \\ \text { Frac not searching in first qtr } & 0.0879 & 0.0298 & 0.0252\end{array}$

second-period unemployment almost as high as first-period unemployment, and then search very hard in the second period of unemployment, so that post-UI unemployment is low. This implies a pattern of job finding that conflicts with the findings of Meyer (1990). At $D^{S}=0.1$, we observe that the probability of job finding in the first period of unemployment is $36 \%$, while in the second period it rises to $64 \%$, which is much too large an increase in probability. At $D^{S}=0.2$, the probabilities are $37 \%$ and $57 \%$, respectively; these are both lower than we would like, but they involve a jump in job finding of reasonable magnitude.

The second-to-last line of Table 3 also reports the change in the worker's probability of unemployment when the UI benefit is raised from 0.33 to 0.36 , which is roughly a rise of four percentage points in the replacement ratio. This is a purely partial equilibrium calculation of the worker's response to UI, holding $R, \pi$, and $w$ fixed. We showed above that according to Solon's data, a $1 \%$ rise in the replacement ratio should lead to a change in unemployment of 0.0005 ; so we should expect a change of 0.002 here. The $D^{S}=0.2$ and $D^{S}=0.3$ cases match this prediction very well, while the change in unemployment of 0.0043 in the $D^{S}=0.1$ case again shows too much sensitivity in the response to UI for consistency with the data. 
Table 4: Effects of $Z$ when $D^{S}=0.2$.

$Z=0.4 \quad Z=0.6 \quad Z=0.8$

$\begin{array}{lrrr}\text { Std dev of consumption } & 0.0723 & 0.0707 & 0.0702 \\ \text { Avg U/E cons ratio } & 0.9508 & 0.9603 & 0.9642 \\ \text { Cert eq of cons/avg cons } & 0.9958 & 0.9958 & 0.9959 \\ \text { Cons innov due to job loss } & -3.50 \% & -2.96 \% & -2.87 \% \\ \text { Total unemployment } & 0.0763 & 0.0760 & 0.0749 \\ \text { 1st qtr unemp } & 0.0362 & 0.0362 & 0.0363 \\ \text { 2nd qtr unemp } & 0.0229 & 0.0244 & 0.0253 \\ \text { Post-UI unemp } & 0.0173 & 0.0155 & 0.0132 \\ \text { 1st qtr prob of job finding } & 0.3664 & 0.3278 & 0.3013 \\ \text { 2nd qtr prob of job finding } & 0.5650 & 0.6094 & 0.6556 \\ \text { Post-UI prob of job finding } & 0.5762 & 0.6151 & 0.6597 \\ \text { Change in u from raised UI } & 0.0025 & 0.0021 & 0.0038 \\ \text { Frac not searching in first per } & 0.0298 & 0.0221 & 0.0240\end{array}$

In Table 4, we look at the impact of a rise in $Z$. As we raise $Z$, we see a pattern emerging similar to that discussed above: second period unemployment rises, while post-UI unemployment falls, as people search less hard initially in the knowledge that they can find jobs easily later on. In fact, in some of our calculations, a rise in $\mathrm{Z}$ was observed to raise second-period unemployment sufficiently to lead to a rise in overall unemployment. Another problematic observation as we raise $Z$ is the innovation in consumption which results from job loss. Gruber (1994) reports that workers' consumption typically falls by $7 \%$ upon job loss, and by much more at lower replacement ratios. Hence all of our calculations imply an innovation which is substantially too small - and raising $Z$ only makes the innovation smaller. ${ }^{30}$ The explanation for the smaller innovation is again related to the ease of job finding; workers need not cut back so strongly on consumption when they are confident of quickly finding a job.

\footnotetext{
${ }^{30}$ The small consumption innovation in our calculations may be partly explained by the separability between consumption utility and work disutility assumed in our statement of the worker's problem. If workers actually have a somewhat greater need for consumption expenditure when working, this would make observed consumption innovations larger than those calculated from the model, even if the model is otherwise correctly calibrated.
} 
On the basis of this variety of observations and calculations, we will work with $Z=0.4$ and $D^{S}=0.2$ as our baseline parameterization. Since these values are not very precisely identified by the data, we will report several specifications for robustness, but this does not change our results greatly. ${ }^{31}$ Unfortunately, no specification matches the data as closely as we would like. Search is under all these parameters somewhat too low, resulting in unemployment rates higher than intended; but as discussed above, lowering $D^{S}$ or raising $Z$ leads to unrealistically high employment elasticities without lower unemployment. Also, consumption innovations are everywhere too low. We will come back to consider the importance of these failures of the model after we analyze the results of several equilibrium calculations.

\section{Results and conclusions}

\subsection{Characteristics of the baseline model}

Before studying the impact of UI, we describe our baseline equilibrium. We pay particular attention to the aggregate observations which we targeted in our parameterization, and we also analyze the distributions of consumption and asset holdings. Recall that the baseline assumes payments of 0.33 to the unemployed and retired; in the equilibrium reported here, this is $34.4 \%$ of value added, or $42.9 \%$ of the wage. Table 6 shows that the equilibrium unemployment rate is $7.6 \%$, somewhat higher than intended, which corresponds to an average probability of job finding per quarter of $47.4 \%$. Most of these unemployed are in their first two quarters of unemployment; the UI-eligible rate of unemployment is $5.9 \%$. The large majority of unemployed workers do in fact prefer to have a job; only $1.9 \%$ choose to set search intensity equal to zero. Search and unemployment behavior is analyzed in greater detail below.

The interest rate is at $1.58 \%$, close to our target, which shows that our assumptions about asset supply and demand are roughly compatible. We find a

\footnotetext{
${ }^{31}$ In particular, varying the two parameters in such a way as to keep $Z$ roughly equal to two times $D^{S}$, over a moderate range, has little effect on the equilibrium.
} 
capital stock equal to 8.3 times value added. Our output share observations are also encouraging; labor's share of value added is $65.7 \%$, which includes taxes paid to support worker benefits, totalling $10.1 \%$ of value added. Investment is $20.5 \%$ of value added, and the remaining $13.8 \%$ of output is paid as dividends. Hiring expenditure (which is not counted as part of value added) is $1.7 \%$ of output, almost as low as intended.

Workers' consumption and savings behavior is analyzed in Tables 7 and 9. Average consumption is $79.5 \%$ of value added; its standard deviation is $7.2 \%$ of value added. The variation in consumption is due both to a gradual increase in consumption over the life cycle as workers accumulate assets, and to the differences in consumption due to employment and unemployment. We see that consumption rises from 0.7152 in the first ten years of working life to 0.8721 in the last ten years of retirement, with a particularly large initial jump as consumers save substantially in their first years of work. Assets rise rapidly over the life cycle, peaking at over seventeen times quarterly value added at retirement. For comparison, Table 10 recalls median asset holding information reported in Hubbard, Skinner, and Zeldes (1995) for different age groups of high-school educated US workers. It is useful to look at medians rather than means, and to restrict ourselves to a single education group, in order to downplay some of the dispersion in asset holdings that shows up in US data due to types of individual heterogeneity not analyzed here. The US data for this class of workers show wealth levels fairly similar to our model, though the asset profile in our model is more sharply peaked. ${ }^{32}$

There are several ways of looking at the impact of labor market shocks on consumption. We see from Table 9 that consumption of the unemployed early in life is only around $91 \%$ of that of the employed, rising to about $96 \%$ before retirement. Since workers start with zero assets, they are forced to cut consumption drastically if they become unemployed early in life; later on they are better protected by their stock of assets. We also calculate the

\footnotetext{
${ }^{32}$ In the data reported by Hubbard et. al., it is rather surprising to observe that assets fail to decline for the oldest age group of high school educated workers. However, for other education groups they discuss, assets do decline substantially near the end of life.
} 
average innovation in consumption which occurs as a result of job loss, as a percentage of current average consumption. This is large both at the beginning of life, when a small buffer stock leads to large cutbacks in consumption due to unemployment, and at the end of life, when the short remaining working period implies that an unemployment spell may take up a non-trivial fraction of remaining working time. ${ }^{33}$ The standard deviation of consumption is also high both at the beginning and the end of life. The lack of a buffer stock makes consumption variable early in life, while at the end of life, the high variability of consumption is the result of many years of drift in asset levels. Although consumption does not follow a pure random walk here, good or bad luck in the labor market does cause workers' expected lifetime wealth levels to diverge over the years, making consumption gradually more variable. ${ }^{34}$

Table 7 summarizes the consumption distribution by computing the certainty equivalent of consumption. This is the non-random quantity of consumption which would yield the same level of utility (ignoring search and work disutility) as the actual distribution of consumption. ${ }^{35}$ We do not find large losses in utility due to consumption variability in this equilibrium; the certainty equivalent of consumption is $99.58 \%$ of the level of average consumption, given the $42.9 \%$ replacement ratio. This suggests either that there is little scope for insurance in this economy, or that insurance needs are already well-fulfilled at the baseline UI benefit level of $42.9 \%$ of the wage.

Table 9 also describes the distribution of unemployment across the life cycle. The fraction of individuals in their first period of unemployment is fairly constant over time, since it is simply a constant $\delta$ times the level of

\footnotetext{
${ }^{33}$ Engen and Gruber (1995) and Dynarski and Sheffrin (1987) both report evidence suggesting that younger workers may be more responsive to unemployment risk than older workers, but Gruber (1994) reports the opposite.

${ }^{34}$ Growing dispersion in consumption over the lifetime is documented in Deaton and Paxson (1994).

${ }^{35}$ Let average consumption utility in the baseline model be $v$; note that this does not include search or work disutility. Then the certainty equivalent $e$ satisfies $(1 / \alpha)(e+\underline{\chi})^{\alpha}=v$. If average consumption in the baseline case is $\bar{c}$, then the claim in Table 7 is that $e=0.9958 \bar{c}$. Note also that welfare calculations in this paper are stated in terms of undiscounted averages.
} 
employment. The fraction of individuals in their second period of employment rises as people get older, for older workers have larger buffer stocks and a shorter potential duration of employment and hence search less. In Table 8, we see that the unemployment rate of $7.6 \%$ can be decomposed into $3.6 \%$ who are in the first period of an unemployment spell, $2.3 \%$ who are in the second period, and $1.7 \%$ who are in the third or later period of a spell, so that they are ineligible for UI. In the first period of unemployment, $2.9 \%$ of individuals choose not to search at all; they know they have one more period of UI eligibility, and hence prefer not to find a job yet. After the first period, the fraction choosing not to search drops to around $1 \%$, as people know they have no future UI eligibility in the current unemployment spell. The greater urgency of job finding in the second and later periods of unemployment spells is also reflected in the rise in the probability of job finding among those who do search, from $37 \%$ in the first period of a spell to $57 \%$ probability thereafter.

\subsection{Effects of UI in the baseline model}

In Tables 11 and 12, we turn to the effects of changing the replacement ratio. The $b^{U}=0.33$ case is the baseline we have examined in earlier tables; we see that raising the benefit from 0.1 to 0.6 amounts to a rise in the replacement ratio from $12.95 \%$ to $78.23 \%$, requiring tax levels which rise from 0.1223 to 0.1654. ${ }^{36}$ Table 11 shows that this rise in the replacement ratio leads to an increase in the unemployment rate from $5.9 \%$ to $10.5 \%$, and a resulting decline in output from 0.9691 to 0.9425 in units of goods. This decline in value added is caused not only by the decline in the number of employed workers, but also by a decline in the capital stock from 8.1 to 7.8 in units of goods. On the other hand, recruitment costs decline from $2.5 \%$ of value added to $0.8 \%$ of value added as the UI benefit is increased, which helps explain the fact that the percentage decrease in output is considerably smaller than the percentage decrease in employment. We also observe small decreases in the interest rate and in the

\footnotetext{
${ }^{36}$ The social security benefit is being held constant at $b^{R}=0.33$ in our calculcations, so taxes must be non-zero even when the unemployment benefit is zero.
} 
wage as UI is increased. There are large changes in the matching rates $\pi$ and $q$ as more unemployed and less hiring expenditures enter the matching function.

Table 12 demonstrates that the optimal replacement ratio, in terms of steady state average utility, is around $47 \%$, where $b^{U}=0.36$. Although this is not very low, the benefits of UI are quantitatively very small, and its optimal level is determined by somewhat surprising factors. First, note that average consumption declines from 0.7697 (in goods units) to 0.7499 as the UI benefit is raised from 0.1 to 0.6 , while the standard deviation of consumption only declines from 0.0741 to 0.0702 . Since we previously noted that the certainty equivalent of consumption, at the baseline replacement ratio, is $99.58 \%$ of average consumption, the large drop in average consumption due to the provision of unemployment insurance bodes ill for its utility impact. Note also that the ratio of consumption of the unemployed to that of the employed decreases as UI is raised, evidence that UI is failing to smooth consumption. Similarly, although the level of search intensity and the innovation in consumption due to job loss both drop slightly as UI is initially raised from 0.1 , both increase thereafter. Again, this suggests that people are becoming less well insured, due to higher unemployment, when UI is high.

At the end of Table 12, we report certainty equivalent calculations which show just how small the benefits of UI are in this economy. The consumption utility gain figures show the difference between the consumption utility at the given level and at the baseline level of 0.33 . These are expressed in terms of the certainty equivalent consumption levels, as a fraction of baseline average consumption. The positive signs on these numbers show us that even at a UI benefit of 0.1 , workers' consumption utility is worth $0.919 \%$ more, as a percentage of baseline average consumption, than the consumption utility associated with a benefit of 0.33 . In fact, in terms of consumption only, increases in UI benefits steadily decrease welfare at every level above 0.1 .

The impact on search utility and work utility is expressed in the same units as the consumption utility changes. We see that the impact on search utility is 
much smaller than that on consumption utility, but it goes in the same direction; search utility is $0.13 \%$ better at $b^{U}=0.1$ than it is at $b^{u}=0.33$. Again, this refers to a utility change equivalent to a $0.13 \%$ change in baseline average consumption. The increase in search disutilility as UI is increased comes about as more search effort must be expended on average since the unemployment rate is higher. On the other hand, less work disutility is expended when unemployment is higher; this is a gain in welfare, which turns out to be quite large. The table shows that at $b^{U}=0.1$, individuals' work disutility is worse, by $1.19 \%$ of baseline average consumption, compared to when $b^{U}=0.33$.

The net effect of the three changes in utility, due to changed consumption, changed search, and changed work, is reported in the final line of the table. The highest utility level observed is that at $b^{U}=0.36$, when the replacement ratio is $46.7 \%$; thus the optimal replacement ratio is not very low. However, the net change in utility due to UI is very small; the overall welfare gain in going from $b^{U}=0.1$ to 0.36 is only worth $0.17 \%$ of baseline average consumption. Thus while UI does not appear to substantially harm the economy at low replacement ratios, there is no sign that it has a major positive effect. ${ }^{37}$ Moreover, as emphasized above, the cause of the mild improvement as UI is raised from 0.1 to 0.36 is not associated with consumption smoothing; instead, it is due to decreased work effort.

However, the pattern of welfare changes caused by UI is not as strange as it may seem. After all, in a classical competitive equilibrium, the marginal product of labor is equated to the worker's cost of work. Decreasing the level of labor used in such an economy thus leads to a fall in output which is approximately matched in size by a decline in costs borne by the worker. If the initial equilibrium is at a smooth optimum, such a distortion of labor use will lead to a net welfare loss which is only of second order.

\footnotetext{
${ }^{37}$ It is also important to notice that as we increase UI above its optimum, the welfare losses get larger much more quickly; there is a net loss worth $0.37 \%$ of baseline average consumption as $b^{U}$ is increased from 0.5 to 0.6 .
} 
How close are we, then, to the competitive case? We can get some idea by computing the surplus associated with work in our equilibrium; for a competitive model, of course, it would be zero. Our wage equation was

$$
w-D^{W} / c^{\alpha-1}=\beta\left(A \gamma n^{\gamma-1} k^{1-\gamma}-D^{W} / c^{\alpha-1}\right)
$$

Here the marginal product of labor $A \gamma n^{\gamma-1} k^{1-\gamma}$ is the gross gain in output available to the economy from work, while $D^{W} / c^{\alpha-1}$ is the gross disutility cost associated with performing the work; the net gain is just the difference between the two, which we have called the surplus. Evaluated at our equilibrium, the marginal product of labor is 0.9443 , the disutility of work, scaled by the marginal utility of average consumption, is 0.5905 , and the surplus is thus 0.3538, slightly over one third the marginal product. Although the surplus is non-trivial, we nonetheless see that offsetting changes in consumption utility and work disutility are likely to be a large part of the impact of UI. We can reasonably expect gross welfare changes to be rather larger than net welfare changes.

\subsection{Partial equilibrium comparisons}

In this section, we conduct two other experiments which shed light on the mechanisms underlying our economy's reaction to a UI program. First, we report the worker's partial equilibrium response to an increase in UI- that is, the change in worker behavior and well-being when the replacement ratio is raised without any effect on the prices $R$ and $w$ or the job finding rate $\pi$. This shows us how much scope there would be for welfare improvements from UI if its imposition had no effect on the equilibrium environment of the worker. Second, we consider the impact of UI in an economy where the interest factor $R$ is fixed. This can be interpreted as the effect of UI in an open economy which is small enough to have no influence on the world interest rate, and it allows us to compare the importance of the effects of UI which operate through the labor market to those which operate through capital accumulation.

In Table 13 we show the partial equilibrium effect of a change in UI benefits on individual behavior under the assumption that $R, w$, and $\pi$ remain constant. 
We fix these three variables at their baseline equilibrium values, as reported in Table 6. Naturally, this means that we report only effects on worker behavior in the table - it makes no sense to ask how the firm's behavior is changed when we are not closing the model with aggregate consistency conditions.

The change in unemployment here allows us to get an idea of the size of the moral hazard effect: we can ask how much unemployment changes due to a decreased willingness to search for jobs, abstracted from any change in the probability of finding jobs. Comparing Tables 11 and 13, we notice that in partial equilibrium, the unemployment rate rises from 0.06733 at $b^{U}=0.1$ to 0.07647 at $b^{U}=0.33$, due to a fall in workers' average search intensity from 0.4648 to 0.3520 . In our general equilibrium baseline, the corresponding rise is from an unemployment rate of 0.05877 to 0.07647 , which is almost twice as large. Hence we conclude that moral hazard accounts for roughly half the general equilibrium change in the unemployment rate as UI rises. The remainder, necessarily, is caused by changes in firms' recruitment activity, which declines from $2.5 \%$ to $1.7 \%$ of value added in general equilibrium, leading to a decline in the job finding rate $\pi$ from 1.6 to 1.1. Note also the interesting contrast in search behavior. While in partial equilibrium search falls from 0.4648 to 0.3510 , in general equilibrium it rises slightly from 0.3399 at $b^{U}=0.1$ to 0.3510 at $b^{U}=0.33$. Thus we conclude, perhaps surprisingly, that the fall in job finding probability $\pi$ that occurs in the general equilibrium model is leading to a rise in search intensity.

Unlike the general equilibrium version of the model, where average consumption declines from 0.7697 to 0.7633 as UI is raised from its minimum reported level to its baseline level, here average consumption rises by a similar magnitude, from 0.7580 to 0.7633 . This is no surprise, for raising UI payments without affecting prices or job finding rates makes workers unambiguously better off. The change in the standard deviation of consumption due to UI is roughly the same in general and partial equilibrium. However, the average ratio of consumption of the unemployed to that of the employed, and the consumption innovation due to job loss, clearly show consumption smoothing effects from a partial equilibrium increase in UI, as the former increases and the 
latter decreases with UI. In contrast, in the general equilibrium version of the model, both measures change by much smaller amounts, and the average ratio of consumption of the unemployed to that of the employed actually goes in the wrong direction. Thus, although UI could smooth the consumption differences between the unemployed and the employed in an ideal world where it had no impact on the overall economy, in general equilibrium its tendency to lower the rate of job finding $\pi$ sufficiently increases the riskiness of the unemployed state that the consumption gap between the unemployed and the employed is not ameliorated.

Another contrast between general equilibrium and partial equilibrium is seen in saving behavior. In partial equilibrium, we see that the influence of UI on average asset holdings is both very small and non-monotonic. Since a rise in the UI benefit both makes the individual wealthier and reduces the risk she faces, the non-monotonicity of asset holding is reasonable. In general equilibrium, on the other hand, assets decline strongly as UI rises from 0.1 to 0.33, falling from 8.6623 to 8.3762 , which is a response to the decline in the interest rate from $1.597 \%$ to $1.584 \%$. We conclude that savings in our model economy are driven much more strongly by the interest rate than they are by precautionary saving factors such as the level of UI.

Unsurprisingly, a welfare analysis of the partial equilibrium shows that UI is extremely beneficial when it can be delivered without affecting prices or job finding rates. Consumption utility, search disutility, and work disutility are all improved by a rise in the replacement ratio, as workers consume more, consume more smoothly, and search and work less. Since the various changes no longer offset each other, net benefits are large: workers are better off by $1.353 \%$ of baseline average consumption in going from a benefit of 0.1 to 0.33 , and would be still better off at higher UI levels. Since the decline in work is smaller in partial equilibrium than in general equilibrium, the decline in work disutility is only worth $0.532 \%$ of baseline average consumption, instead of $1.1893 \%$ in general equilibrium. Consumption utility improves by $0.759 \%$ of baseline average consumption from this change in the replacement ratio, instead of declining by $0.9186 \%$ as it does in general equilibrium. It is also 
telling to notice that the rise in average consumption from 0.7580 to 0.7633 in partial equilibrium amounts to $0.694 \%$ of the baseline average consumption level of 0.7633 . The decline in average consumption in general equilibrium is from 0.7697 to 0.7633 , which is $0.838 \%$ of baseline average consumption. Note that these changes in baseline average consumption are roughly equal to the corresponding changes in the certainty equivalent measures of consumption utility. This illustrates the claim that there is little role for consumption smoothing improvements in this economy. The impact of UI on consumption utility is well proxied by its impact on average consumption; the variability of consumption need not be considered.

In reporting the impact of UI on an economy with fixed $R$, we will show both effects on worker and firm behavior, for this is a well-defined experiment as long as we assume that the economy is in an international environment where the world interest rate is negligibly affected by demand and supply for assets in the particular country under study.

In Table 14, we find that unemployment, value added, recruitment, capital, and the matching coefficients $\pi$ and $q$ all change slightly more in the fixed $R$ case than they do in general equilibrium. In the absence of any change in the interest rate, the main impact on firm behavior from an increase in UI is that taxes must rise, making it more expensive to hire workers, and thus less profitable to produce output. Thus firms cut back on hiring and investment. In general equilibrium, this decline in the returns to production activity causes the interest rate to fall as firms engage in less borrowing (recall from our partial equilibrium calculations that UI has little direct effect on workers' saving incentives.) This decrease in the interest rate would mitigate the fall in hiring and investment in general equilibrium; since $R$ is fixed here, the adjustments are larger than they are in general equilibrium.

In a somewhat surprising contrast, we notice that average consumption rises slightly with UI in this experiment. Note that since individuals are net savers, a fall in the interest rate implies a decline in their effective lifetime wealth. Considering labor market income only, UI increases income when unemployed; in fact, wages are slightly higher here as well when UI is increased, due to 
a rise in the marginal product of labor. In our equilibrium, these increases are large enough to increase expected labor market income in spite of the higher probability of unemployment. ${ }^{38}$ In general equilibrium, the fall in the profitability of hiring would drive down $R$, making workers poorer; yet here this does not occur, and without such an interest rate effect, UI has a sufficiently positive effect on the income stream to raise average consumption.

We can also compare the total value of the firms in the economy, which is the sum of capital plus the value $n / q$ of hiring, both reported in Table 14 , to the value of assets held, in Table 15. In general equilibrium these must be equal, but here they only match up for the $b^{U}=0.33$ case from which our $R$ was derived. With $R$ fixed by international trade, workers save at the high rate of return offered by the international economy, which leads to increasing asset holdings with UI. Firms only invest up to the point where the rate of return on their investment matches that in the international economy; hence their total asset value declines as taxes are raised to support UI.

Since consumption grows with UI in this experiment, benefits of UI here are large, and the optimal replacement ratio is at least as large as the highest level shown in these tables. Raising the UI benefit from 0.1 to 0.33 raises consumption utility by $0.3 \%$ of baseline average consumption, while decreasing work disutility by $1.1 \%$ of baseline average consumption. This goes to show that the impact of UI on the interest rate is potentially important; the change in consumption utility when interest rate effects are taken into account is less by a full $1 \%$ of baseline average consumption than it is when we fix $R$.

\subsection{Sensitivity to parameter changes}

We now compare four alternative specifications to examine the robustness of our results. We increase risk aversion to $\alpha=-1$ and $\alpha=-2$, since clearly the degree of risk aversion is critical to the value of UI in our economy, and the logarithmic utility in our baseline specification is on the low side of accepted

${ }^{38}$ The unconditional expectation of labor market income $y^{W} \equiv\left(1-u^{T O T}\right) w+u^{U I} b^{U}$ rises slightly from 0.7304 to 0.7308 as $b^{U}$ is increased from 0.1 to 0.33 . 
parameterizations of risk aversion. The wage equation we used in section 3.3 imposes a strong relationship between $\alpha$ and the disutility of work $D^{W}$, so we raise disutility to $D^{W}=0.98$ for the $\alpha=-1$ case and to $D^{W}=1.2$ for the $\alpha=-2$ case to ensure that wages and search behavior will be compatible with the altered levels of risk aversion. As a second comparison, we return to logarithmic utility but explore different search effort parameters $Z$ and $D^{S}$. We compare our baseline to the alternative case of $Z=0.2$ and $D^{S}=0.1$, and to the case of $Z=0.8$ and $D^{S}=0.2$.

In Tables 16, 18, and 19, we look at the effects of changes in $\alpha$. There are several main qualitative changes relative to our baseline equilibrium. First, we notice a substantial rise in the equilibrium interest rate as risk aversion is raised. Note that in our baseline, the interest rate is greater than the time discount rate, and that consumption grows substantially over time. The interest rate is raised above the discount rate to encourage workers to accumulate an amount of assets equal to the value of the firms. With an $\alpha$ that is larger in absolute value, workers are not only more risk averse, but are also less willing to substitute consumption intertemporally, requiring a higher interest rate to convince them to postpone consumption enough to accumulate assets equal to the value of the firms. In conjunction with the higher interest rate, we observe a lower capital stock and lower output as $\alpha$ rises in absolute value, since firms choose to purchase less capital as the interest rate rises.

A second major effect is that unemployment is substantially lower. Given their higher risk aversion, we observe that workers choose a higher level of search, because they are more averse to the possibility of lost consumption. This greater search causes them to find jobs sooner, lowering the unemployment rate, which then raises the job finding rate $\pi$ and lowers $q$ as observed in the table. We recall from our analysis of the partial equilibrium and general equilibrium versions of the model that higher $\pi$ lowers search in this economy; thus the observed increase in search is actually somewhat lower than it would be without the change in $\pi$. Also, we observe that firms hire more to make up for the lower rate of matching $q$. 
A third, obvious, difference in our equilibrium as risk aversion is changed is that workers come to care much more about consumption variation. We see that the ratio of the certainty equivalent of consumption to average consumption declines to 0.9913 in the $\alpha=-1$ case and to 0.9807 when $\alpha=-2$, much lower than our baseline, though not necessarily low enough to ensure large gains from UI. At the same time, consumption innovations due to job loss are much smaller than in the baseline, and the average ratio of unemployed consumption to employed consumption is higher than in the logarithmic utility case; thus we see that individuals are managing to insure themselves more fully in this equilibrium than in the baseline equilibrium. Since assets are not much higher here than in the baseline, it appears that most of the additional self-insurance is coming through the higher search intensity and resulting lower unemployment rate in this equilibrium. Note that it is not clear whether the logarithmic or $\alpha=-1$ case fits the data better: the lower unemployment and the pattern of job finding in the $\alpha=-1$ case look more like the stylized facts we used to parameterize our model; however, the small consumption innovations that arise when risk aversion is higher are at odds with the data.

Coming to the welfare analysis in Table 18, we see that for $\alpha=-1$, selfinsurance is still powerful enough that UI has very little role to play in welfare improvement. As in our baseline, UI leads to a fairly large loss in welfare due to lower average consumption, offset by a fairly large gain in welfare due to less work effort. Net benefits are very small; the optimal replacement ratio is around $25 \%$ but represents a welfare gain of only about $0.17 \%$ of average consumption. The fact that the optimum is lower here than in our baseline need not be a surprise when it is calculated as a small net gain from the difference of two large gross changes.

However, there is real evidence for welfare gains from consumption smoothing in the $\alpha=-2$ case. Consumption utility still decreases with UI, but these changes are only about half as large as the decreases in work disutility, leading to a non-trivial net benefit. Also, the ratio of average consumption of the unemployed to that of the employed increases substantially due to UI, while the consumption innovation resulting from job loss gets smaller. Looking at the 
size of the change in consumption utility, we can calculate that the decline in average consumption as UI is increased from 0.1 to 0.33 is $0.537 \%$, while the change in the certainty equivalent of consumption utility is only $0.252 \%$. The large difference in the size of these two percentage changes is attributable to welfare gains from consumption smoothing.

For $\alpha=-2$, we find a remarkably high optimal replacement ratio- evidently over $100 \%$. This substantial change in our analysis is driven by several factors which go beyond the greater consumption smoothing needs of more risk averse consumers. First, since higher search yields lower unemployment in this equilibrium than in our baseline, raising UI has a relatively smaller tax impact on firms. Increased UI therefore raises unemployment less and decreases consumption less than it does in the baseline model. With a smaller rise in unemployment due to UI, there is less tendency for UI to drive up the effective level of risk that workers face; hence raising UI now leads to observable consumption smoothing, as evidenced by the direction of change of the consumption innovation and the ratio of unemployed to employed consumption.

Two investment externalities also play a role. The effect of UI on the capital stock is much less negative for $\alpha=-2$ than for logarithmic utility. Since lower willingness to shift consumption over time leads to a larger difference between the interest rate and the time discount rate here than in the baseline, there is potential for a larger drop in the interest rate, from 0.01953 to 0.01882 as UI is raised from 0.1 to 0.7 . The interest rate decrease allows for a small, nonmonotonic change in the capital stock, unlike the monotonic decrease in capital found in the baseline case. Also, as demonstrated for a simplified version of the model in Costain (Nov. 1997), the wage bargaining solution used here is more likely to lead to overhiring, for a given bargaining share $\beta$, than is the standard model analyzed in Hosios (1990). Thus part of the effect of increased UI is a fairly large decrease in hiring costs, from $4.1 \%$ of value added to $1.9 \%$ of value added, over the range of UI considered here. While such an effect is present in the logarithmic utility case as well, when it is combined with larger consumption smoothing benefits, a smaller unemployment rate, and 
a relatively large interest rate drop, the overall benefits of UI become quite large.

In Tables 17, 20, and 21, we compare two different specifications of search effort to our baseline case. Both alternative specifications yield a similar pattern of job search shirking. In the $Z=0.2, D^{S}=0.1$ case, average search is substantially lower, and a much larger fraction of individuals choose not to search at all. For $Z=0.8$ and $D^{S}=0.2$, average search is higher, but the effects on the equilibrium are similar, with a large spread between the probability of job finding in the first period of unemployment and that in later

periods. In both cases, in spite of the initial low search intensity, the late search is effective enough that overall unemployment is lower.

These same tendencies are reflected in the response to unemployment insurance. In Tables 20 and 21, both unemployment and average consumption respond more strongly to UI than in the baseline model. This response is reflected by large gross changes in both the certainty equivalent of work disutility and the certainty equivalent of consumption. As in our previous simulations, however, these two changes largely cancel each other out; net welfare gains from UI are small, and the optimum is at a low level around $20 \%$. We conclude that these specifications imply somewhat too much elasticity of unemployment to the imposition of UI; nonetheless their welfare implications are not very different from our baseline case.

\subsection{Discussion}

In light of these simulations, the primary conclusion we must draw is that our model does not appear to support large consumption smoothing gains from UI. As in Aiyagari (1994), individuals in our model achieve a high degree of consumption self-insurance, even with UI as low as $10 \%$. Mandating an unemployment benefit of up to $40 \%$ has very little impact - either positive or negative - on well-being. With low risk aversion, optimal replacement ratios have typically been around $20 \%$ or $30 \%$, yet actual utility gains, on the order of $0.1 \%$ of baseline average consumption, are so small as to make the precise 
optimum rather irrelevant. Raising the degree of risk aversion to $\alpha=-2$ makes UI much more relevant, yielding utility gains close to one percentage point of baseline average consumption and an optimal replacement ratio which appears to be around $100 \%$.

The nature of the welfare changes arising from an increase in the UI benefit tends to include a fairly large loss in consumption utility, coupled with a similar decrease in disutility of work. At low risk aversion, these two changes tend to cancel each other out. When risk aversion is high enough to lead to a nontrivial welfare gain, as in the $\alpha=-2$ case, the net gain is due to the fact that the decrease in work disutility is substantially larger than the decrease in consumption utility. The small size of the decrease in consumption utility is caused by a gain from consumption smoothing which partially offsets the loss from lower average consumption. Even here, though, much of the the welfare gain from UI is due not to consumption smoothing per se, but to search externalities and to positive effects on the capital stock via changes in the interest rate. Also, we have not observed actual gains in the consumption portion of utility alone in any of our general equilibrium calculations.

This pattern of utility changes should not come entirely as a surprise. We know that in a competitive model at a smooth local optimum, a decrease below optimal labor supply would cause an output decrease equal in value, to first order, to the decrease in labor costs; overall welfare losses would be only second order. Similarly, here, the biggest impacts of the distortionary transfer of UI payments are a decrease in output and consumption, and a decrease in the disutility of work. Although this is a search model, in which matching and production involve a jump in surplus relative to separation and non-production, nonetheless the disutility of work (in comparable units) is about $63 \%$ of the benefit of work, which is the marginal product of labor. In this sense, the model shares some of the same large gross offsetting costs and benefits as in a competitive model. Of course, for an unfortunate worker who has had very poor labor market luck, marginal utility may be much higher, so that the disutility of work is effectively much lower relative to its benefits; for such an individual the surplus associated with work is large. Such individuals do exist 
in our model, and they benefit greatly from UI; however, our overall welfare analysis can be interpreted as showing that such workers are rare enough that the average benefits of UI are not great.

The model employed here is rather more complicated than a simple competitive labor market model, and incorporates a variety of different effects. We see from comparing general equilibrium and partial equilibrium versions of the worker's problem that roughly half the change in unemployment caused by UI can be traced to moral hazard, as workers choose to expend less search effort. From the fixed $R$ version of the model, we see the size of the impact of tax changes on the firm's problem; this version causes a moderately larger change in unemployment than the general equilibrium version in which the decline in the interest rate helps mitigate unemployment. By comparing the fixed $R$ and general equilibrium versions of the model, we also see that interest rate effects are indeed important in this economy. The decline in the interest rate as UI rises represents a decrease in the returns to accumulation when taxes are higher; this interest rate decline is a loss of wealth to the workers, who are net savers over the life cycle.

How far should we trust the results of this model? Arguably, the various ways in which this model conflicts with US data can be summed up as aspects of a single issue: workers, in the model economy, appear better insured than typical US workers. The rather high unemployment rate of $7.6 \%$ calculated in our baseline is indicative of insufficient search by workers due to a low incentive to acquire jobs. This claim is borne out by the decline in unemployment towards $6 \%$ as we increase the incentive to be employed by raising risk aversion. Small consumption innovations from job loss are also a sign of effective insurance. Third, we must consider the quantity of assets accumulated. Our average asset holdings appear consistent with median assets for high school educated workers, though we necessarily underestimated the US capital stock in order to equate asset supply and demand. However, the amount of insurance achieved through this stock of assets may be exaggerated, for several reasons; our model ignores the fact that some assets are highly illiquid and thus may play little insurance role, and we have also ignored other types of risk, such 
as health shocks and random wage growth. If workers' assets in the US are a response to multiple types of shocks, evaluating their consumption smoothing potential in the context of a model with only one type of shock may lead to an overestimate of equilibrium self-insurance.

The fact that we are unable to fit some aspects of the economy better appears to result from our attempt to represent the economy in terms of only one type of individual. As emphasized in the parameterization section of this paper, we must specify a rather low capital stock because we have not allowed for the existence of multiple classes of people with very different saving behavior, as in the US. It is perhaps rather unreasonable to require that all capital be held on the basis of life-cycle incentives, together with the single type of risk considered here. Assuming that much capital is held by risk neutral savers outside of the labor market would allow us to consider a larger capital stock, and would negate or diminish effects of UI that operate through the interest rate. Such a specification might also lead to a greater role for UI. In particular, Carroll and Samwick (1995a,b) have suggested a parameterization of individual behavior with a discount rate substantially higher than the interest rate; this makes workers disinclined to precautionary saving and thus raises the possible benefits of UI. Other sorts of individual heterogeneity also increase the potential for welfare gains from UI; certain classes of workers prone to longer unemployment spells, or the inclusion of additional types of risk, could yield a greater probability of low consumption in equilibrium, and thus make UI more beneficial.

In summary, the ways in which this model appears to conflict with data can be traced to the necessary simplifications involved in a general equilibrium assessment of the interacting effects of UI. We find relatively small net benefits from UI, though with sufficient risk aversion net gains worth almost one percent of aggregate consumption are possible. More realistic, and thus more heterogeneous economies might imply greater net gains; however, we should remember that our exercise has also neglected to model the potential costs of UI associated with the separation decision. 


\section{REFERENCES}

Acemoglu, Daron, and Shimer, Robert. "Efficient Unemployment Insurance." Manuscript. June 1997.

Aiyagari, S. Rao. "Uninsured Idiosyncratic Risk and Aggregate Saving." Q.J.E. August 1994.

Alvarez, Fernando, and Veracierto, Marcelo. "Welfare Effects of Job Security Provisions Under Imperfect Insurance Markets." Manuscript. June 1996.

Anderson, Patricia M., and Meyer, Bruce D. "The Effects of Unemployment Insurance Taxes and Benefits on Layoffs Using Firm and Individual Data." N.B.E.R. Working Paper 4960. December 1994.

Andolfatto, David. "Business Cycles and Labor Market Search." A.E.R 86 (March 1996.)

Baily, Martin Neil. "Some Aspects of Optimal Unemployment Insurance." Journal of Public Economics 10 (1978.)

Barron, John M.; Black, Dan A.; and Lowenstein, Mark A. "Job Matching and On-the-Job Training." Journal of Labor Economics 7 (January 1989.)

Blanchard, Olivier, and Diamond, Peter. "The Beveridge Curve." Brookings Pap. Econ. Activity 1:1989.

Carroll, Christopher D. "The Buffer Stock Theory of Saving: Some Macroeconomic Evidence." Brookings Pap. Econ. Activity 2:1992.

Burdett, Kenneth; Kiefer, Nicholas M.; and Sharma, Sunil. "Layoffs and Duration Dependence in a Model of Turnover." Journal of Econometrics 28 (1980.)

Burdett, Kenneth; Kiefer, Nicholas M.; Mortensen, Dale T.; and Neumann, George R. "Earnings, Unemployment, and the Allocation of Time Over Time." R.E.S. (1984.)

Carroll, Christopher D., and Samwick, Andrew A. "The Nature of Precautionary Wealth." NBER Working Paper 5193. July 1995.

Carroll, Christopher D., and Samwick, Andrew A. "How Important is Precautionary Saving?" NBER Working Paper 5194. July 1995.

Costain, James S. "General Equilibrium Unemployment Insurance: The Exponential Utility Case." Manuscript. November 1995.

Costain, James S. "A Note on Wage Bargaining in Matching Models." Manuscript. February 1996. 
Costain, James S. "Unemployment Insurance in a General Equilibrium Model of Job Search and Precautionary Saving." Dissertation, Univ. of Chicago. August 1997.

Costain, James S. "On the Quantitative Importance of Wage Bargaining." Manuscript. November 1997.

Deaton, Angus. "Saving and Liquidity Constraints." Econometrica 59 (September 1991.)

Deaton, Angus. Understanding Consumption. New York: Clarendon Press. 1992.

Deaton, Angus, and Paxson, Christina. "Intertemporal Choice and Inequality." J.P.E. 102 (June 1994.)

Dynarsky, Mark, and Sheffrin, Steven M. "Consumption and Unemployment." Q.J.E. 104 (May 1987.)

Ehrenberg, Ronald G., and Oaxaca, Ronald L. "Unemployment Insurance, Duration of Unemployment, and Subsequent Wage Gain." A.E.R. 66 (December 1976.)

Ehrenberg, Ronald G., and Smith, Robert S. Modern Labor Economics: Theory and Public Policy. New York: Harper Collins. 1994.

Engen, Eric M., and Gruber, Jonathan. "Unemployment Insurance and Precautionary Saving." Manuscript. April 1995.

Feldstein, Martin. “The Impact of Unemployment Insurance on Temporary Layoff Unemployment." A.E.R. 68 (1978.)

Gruber, Jonathan. "The Consumption Smoothing Benefits of Unemployment Insurance." Manuscript. May 1994.

Hamermesh, Daniel S., and Slesnick, Daniel T. "Unemployment Insurance and Household Welfare: Microeconomic Evidence 1980-93." NBER Working Paper 5315. October 1995.

Hansen, Gary D., and Imrohoroglu, Ayse. "The Role of Unemployment Insurance in an Economy with Liquidity Constraints and Moral Hazard." J.P.E. 100 (February 1992.)

Hopenhayn, Hugo A., and Nicolini, Juan Pablo. "Optimal Unemployment Insurance and Employment History." Manuscript. October 1994.

Hosios, Arthur J. "On the Efficiency of Matching and Related Models of Search and Unemployment." R.E.S. 57 (April 1990.) 
Hubbard, R. Glenn; Skinner, Jonathan; and Zeldes, Stephen P. "Precautionary Saving and Social Insurance." J.P.E. 103 (April 1995.)

Judd, Kenneth L., and Solnick, Andrew. "The Demand for Unemployment Insurance by Risk-Averse Workers." Manuscript. October 1995.

Kimball, Miles S. "Precautionary Saving in the Small and in the Large." Econometrica 58 (January 1990.)

Marston, Stephen T. "Employment Instability and High Unemployment Rates." Brookings Pap. Econ. Activity 1:1976.

Meyer, Bruce D. "Unemployment Insurance and Unemployment Spells." Econometrica 58 (July 1990).

Meyer, Bruce D. "Lessons from the U.S. Unemployment Insurance Experiments." J.E.L. 33 (March 1995).

Millard, Stephen P., and Mortensen, Dale T. "The Unemployment and Welfare Effects of Labour Market Policy: A Comparison of the U.S. and the U.K." Manuscript. June 1994.

Mortensen, Dale T. "Job Search and Labor Market Analysis." In Orley C. Ashenfelter and Richard Layard, eds., Handbook of Labor Economics, v.2, ch.15. Amsterdam: North-Holland. 1986.

Mortensen, Dale T., and Pissarides, Christopher A. "Job Creation and Job Destruction in the Theory of Unemployment." R.E.S. 61 (July 1994.)

Nickell, Stephen J. "Dynamic Models of Labour Demand." In Orley C. Ashenfelter and Richard Layard, eds., Handbook of Labor Economics, v.1, ch.9. Amsterdam: North-Holland. 1986.

Pissarides, Christopher A. "Search, Wage Bargains, and Cycles." R.E.S. 54 (July 1987.)

Pissarides, Christopher A. Equilibrium Unemployment Theory. Cambridge, Mass.: Blackwell. 1990.

Rendon, Silvio. "Job Search and Asset Accumulation under Borrowing Constraints." Manuscript. November 1996.

Sargent, Thomas J., and Ljungqvist, Lars. "The European Unemployment Dilemma." Manuscript. 1995.

Shaked, Avner, and Sutton, John. "Involuntary Unemployment as a Perfect Equilibrium in a Bargaining Model." Econometrica 52 (November 1984.)

Solon, Gary. "Work Incentive Effects of Taxing Unemployment Benefits." Econometrica 53 (March 1985.) 
Valdivia, Victor H. "Evaluating the Welfare Benefits of Unemployment Insurance." Manuscript. November 1995.

Wolinsky, Asher. "Matching, Search, and Bargaining." Journal of Economic Theory 42 (August 1987.)

Yashiv, Eran. "The Determinants of Equilibrium Unemployment." HEC School of Management Working Paper CR600/1997. June 1997.

Zeldes, Stephen P. "Optimal Consumption with Stochastic Income: Deviations from Certainty Equivalence." Q.J.E. 104 (May 1989.)

Zhang, Guang-Jia. "Unemployment Insurance Analysis in a Search Economy." Manuscript. February 1996. 
Table 5: Baseline parameters

\begin{tabular}{|c|c|c|c|c|c|}
\hline \multirow[t]{8}{*}{ Preferences } & $T$ & 180 & Matching technology & $I$ & 1 \\
\hline & $T^{R}$ & 60 & & $\beta$ & 0.5 \\
\hline & $\alpha$ & 0 & & $\delta$ & 0.04 \\
\hline & $\rho$ & 0.015 & & $\mu$ & 2.2 \\
\hline & $D^{W}$ & 0.78 & & $\xi$ & 0.55 \\
\hline & $D^{S}$ & 0.2 & & & \\
\hline & $Z$ & 0.4 & Computational parameters & $\chi$ & $1 / 12$ \\
\hline & & & & $\underline{\chi}$ & $1 / 1200$ \\
\hline \multirow[t]{4}{*}{ Production technology } & A & 0.63 & & $-A_{\min }$ & $-24 \chi$ \\
\hline & $\gamma$ & 0.67 & & $A_{\max }$ & $400 \chi$ \\
\hline & $\delta_{k}$ & 0.025 & & $c_{\max }$ & $40 \chi$ \\
\hline & & & & $\sigma_{\min }$ & -4 \\
\hline \multirow[t]{2}{*}{ Policies } & $b^{U}$ & 0.33 & & $\sigma$ & 0.5 \\
\hline & $b^{R}$ & 0.33 & & $\sigma_{\max }$ & 4 \\
\hline
\end{tabular}

Table 6: Aggregate implications of baseline model

\begin{tabular}{lr} 
Replacement ratio & 0.4285 \\
Interest rate & 0.01584 \\
$\pi$ & 1.1175 \\
Wage & 0.7702 \\
Unemployment rate & 0.07647 \\
UI-eligible unemployment rate $^{a}$ & 0.05915 \\
Average prob of job finding if unemployed $^{a}$ & 0.4735 \\
Capital stock / value added $^{a}$ & 8.2838 \\
Labor's share of value added $^{b}$ & 0.6572 \\
Recruitment expenditures / value added $^{\text {Investment expenditures / value added }}{ }^{b}$ & 0.0174 \\
Tax collected / value added $^{b}$ & 0.2045 \\
Dividend payments / value added $^{b}$ & 0.1012 \\
\hline
\end{tabular}

${ }^{a}$ Time period is one quarter in all calculations.

${ }^{b}$ Note: wage costs + investment + tax collected + dividends $=$ value added. 
Table 7: Distributional implications of baseline model

\begin{tabular}{|c|c|c|c|c|}
\hline & Overall & Employed & Unemployed & Retired \\
\hline Average consumption / VA & 0.7954 & 0.7756 & 0.7407 & 0.8630 \\
\hline Std dev of consumption / VA & 0.0723 & 0.0562 & 0.0742 & 0.0674 \\
\hline Average assets / VA & 8.7293 & 7.8222 & 7.4363 & 11.5389 \\
\hline $\mathrm{CE}$ of cons / avg cons ${ }^{a, b}$ & 0.9958 & 0.9725 & 0.9251 & 1.0816 \\
\hline
\end{tabular}

${ }^{a} \mathrm{CE}$ refers to the certainty equivalent of consumption; this is the constant level of consumption that yields the same utility as the mean of the equilibrium consumption utility distribution. Defined in footnote in Section 4.1.

${ }^{b}$ All columns are divided by overall average consumption.

Table 8: Unemployment and search in baseline model

\begin{tabular}{lrrrr}
\hline & 1st per. of spell & 2nd per. of spell & Post-UI & Overall \\
Unemployment rate & 0.03621 & 0.02294 & 0.01732 & 0.07647 \\
Avg prob of job finding & 0.3664 & 0.5650 & 0.5762 & 0.4735 \\
Fraction not searching & 0.0298 & 0.0086 & 0.0124 & 0.0193 \\
\hline
\end{tabular}



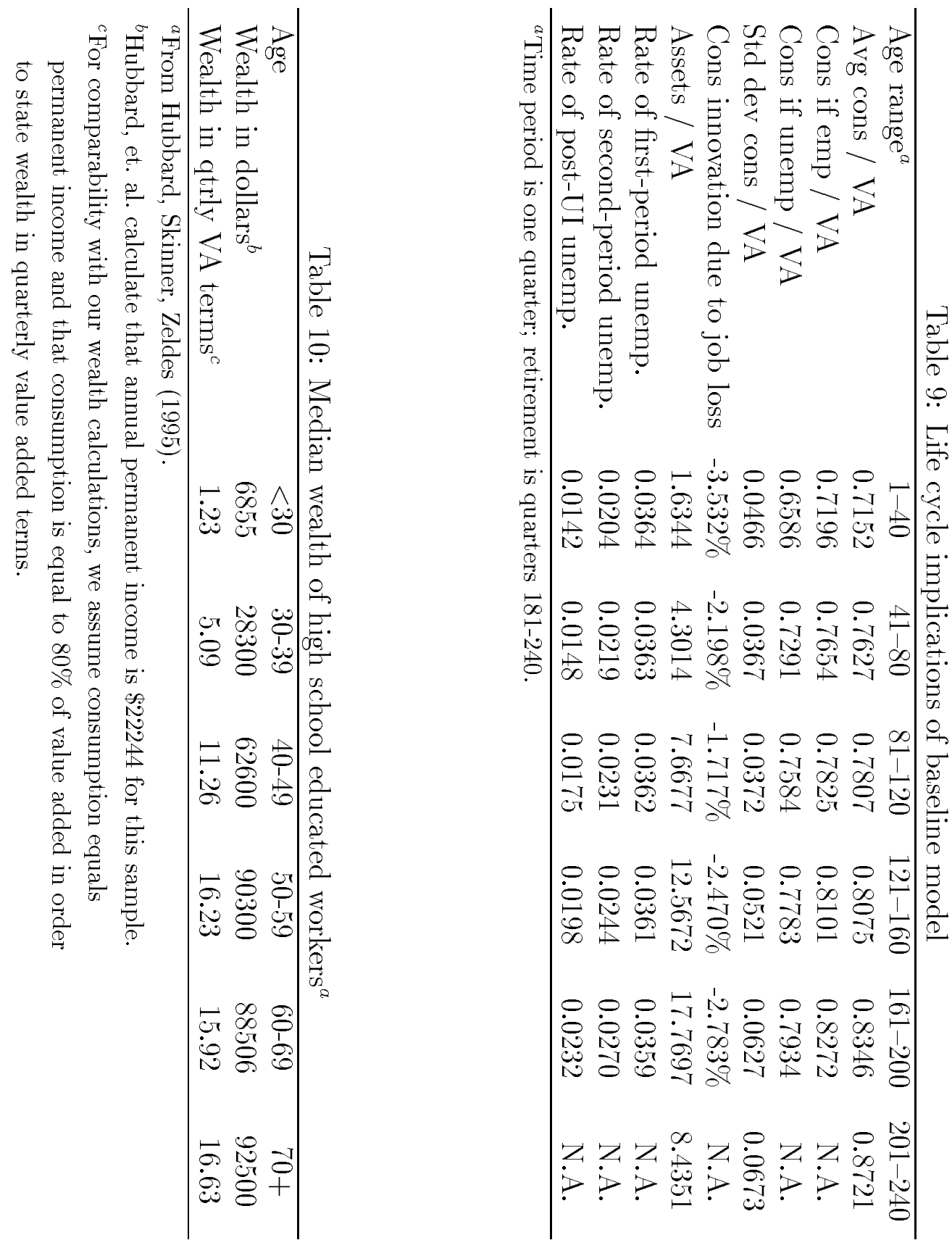


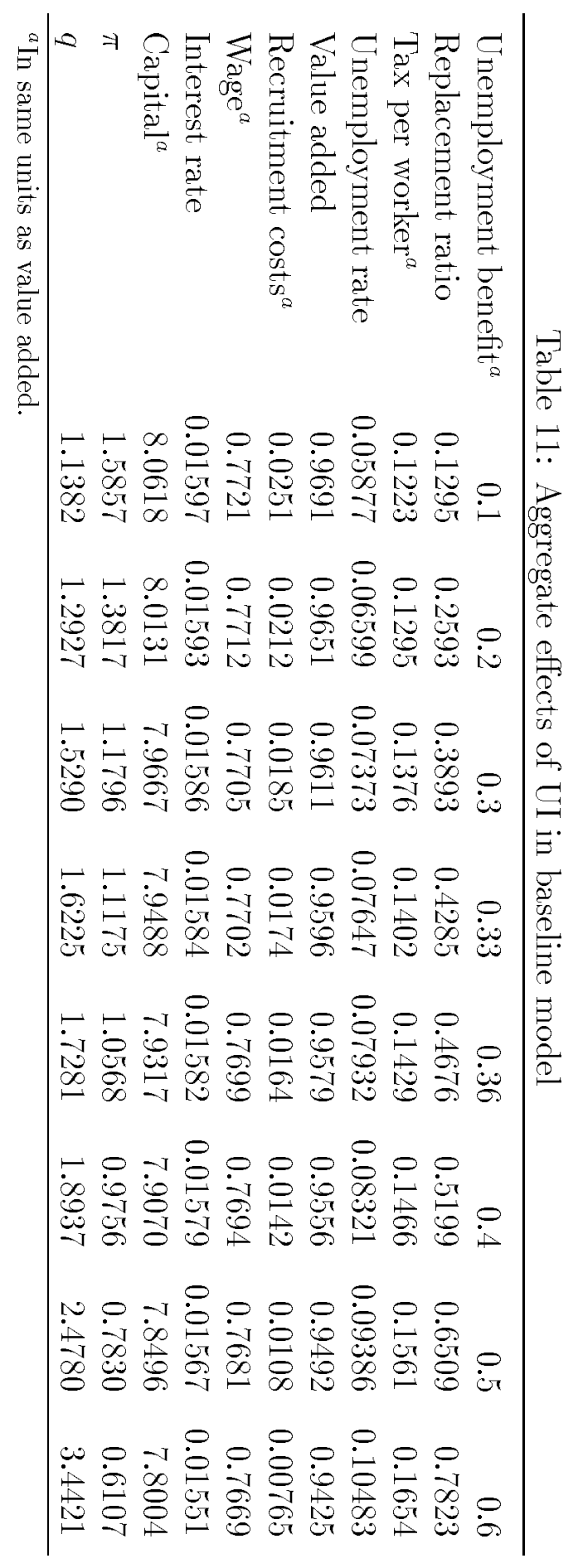




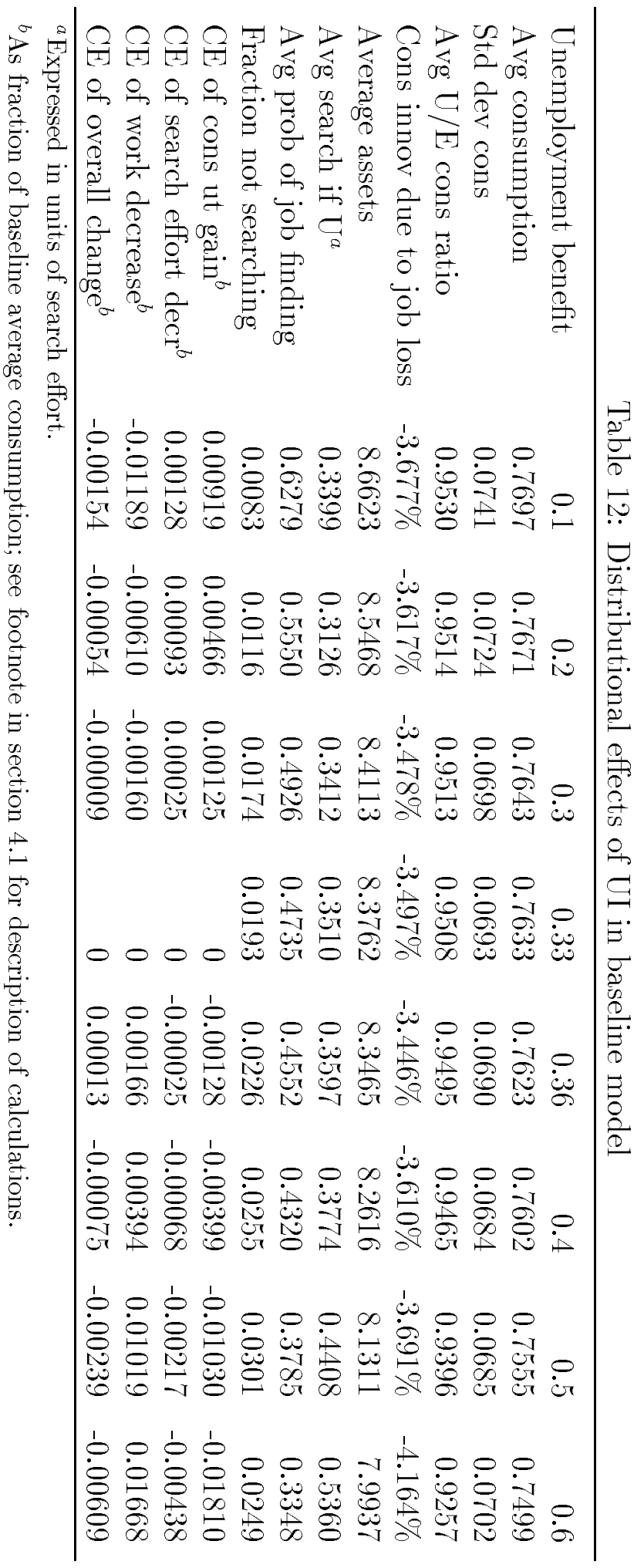


Table 13: Worker's partial equilibrium response to UI

\begin{tabular}{lrrrrr}
\hline Unemployment benefit & 0.1 & 0.2 & 0.3 & 0.33 & 0.36 \\
Unemployment rate & 0.06733 & 0.07072 & 0.07451 & 0.07647 & 0.07811 \\
Average consumption & 0.7580 & 0.7610 & 0.7634 & 0.7633 & 0.7635 \\
Std dev of consumption & 0.0741 & 0.0723 & 0.0701 & 0.0694 & 0.0682 \\
Avg U/E cons ratio & 0.9381 & 0.9433 & 0.9502 & 0.9508 & 0.9517 \\
Cons innovation & $-4.564 \%$ & $-4.080 \%$ & $-3.468 \%$ & $-3.497 \%$ & $-3.441 \%$ \\
Average assets & 8.3756 & 8.4139 & 8.4091 & 8.3762 & 8.3475 \\
Average search & 0.4648 & 0.4045 & 0.3644 & 0.3520 & 0.3434 \\
Avg prob of job finding & 0.5432 & 0.5252 & 0.4870 & 0.4735 & 0.4627 \\
CE of cons ut & -0.00759 & -0.00343 & +0.00001 & 0 & +0.00036 \\
CE of search & -0.00067 & -0.00026 & -0.00005 & 0 & +0.00000 \\
CE of work & -0.00532 & -0.00335 & -0.00114 & 0 & +0.00096 \\
CE overall & -0.01353 & -0.00702 & -0.00119 & 0 & +0.00132 \\
\hline
\end{tabular}


Table 14: Aggregate effects of UI: fixed $R$ case

\begin{tabular}{lrrrrr}
\hline Unemployment benefit & 0.1 & 0.2 & 0.3 & 0.33 & 0.36 \\
Unemployment rate & 0.05722 & 0.06460 & 0.07342 & 0.07643 & 0.07976 \\
Value added & 0.9700 & 0.9662 & 0.9614 & 0.9596 & 0.9575 \\
Recruitment / VA & 0.0275 & 0.0234 & 0.0189 & 0.0175 & 0.0160 \\
Wage & 0.7693 & 0.7699 & 0.7701 & 0.7702 & 0.7702 \\
$\pi$ & 1.6944 & 1.4479 & 1.1963 & 1.1184 & 1.0404 \\
$q$ & 1.0380 & 1.2148 & 1.4981 & 1.6203 & 1.7655 \\
Capital & 8.1150 & 8.0515 & 7.9756 & 7.9497 & 7.9210 \\
$n / q$ & 0.6812 & 0.5775 & 0.4639 & 0.4269 & 0.3909 \\
\hline
\end{tabular}

Table 15: Distributional effects of UI: fixed $R$ case

\begin{tabular}{lrrrrr}
\hline Unemployment benefit & 0.1 & 0.2 & 0.3 & 0.33 & 0.36 \\
Average consumption & 0.7608 & 0.7625 & 0.7630 & 0.7631 & 0.7633 \\
Std dev consumption & 0.0674 & 0.0684 & 0.0686 & 0.0692 & 0.0701 \\
Avg U/E cons ratio & 0.9508 & 0.9525 & 0.9516 & 0.9506 & 0.9491 \\
Cons innovation & $-4.024 \%$ & $-3.559 \%$ & -3.454 & $-3.518 \%$ & $-3.458 \%$ \\
Average assets & 8.2395 & 8.3157 & 8.3481 & 8.3660 & 8.3960 \\
Average search & 0.3248 & 0.3011 & 0.3372 & 0.3510 & 0.3636 \\
Avg prob of job finding & 0.6460 & 0.5678 & 0.4949 & 0.4738 & 0.4524 \\
CE of cons ut & -0.00306 & -0.00097 & -0.00033 & 0 & -0.00016 \\
CE of search & +0.00124 & +0.00111 & +0.00031 & 0 & -0.00032 \\
CE of work & -0.01116 & -0.00690 & -0.00178 & 0 & +0.00192 \\
CE overall & -0.01297 & -0.00677 & -0.00180 & 0 & +0.00143 \\
\hline
\end{tabular}


Table 16: Equilibrium at different levels of risk aversion

\begin{tabular}{lrrr}
\hline & $\alpha=0$ & $\alpha=-1$ & $\alpha=-2$ \\
Interest rate & 0.01584 & 0.01681 & 0.01934 \\
Unemployment rate & 0.07647 & 0.06959 & 0.06114 \\
Capital / VA & 8.2838 & 8.13 & 7.7588 \\
Recruitment / VA & 0.0174 & 0.0229 & 0.0353 \\
Wage & 0.7702 & 0.7500 & 0.7013 \\
Value added & 0.9596 & 0.9504 & 0.9203 \\
Avg U/E cons ratio & 0.9508 & 0.9668 & 0.9770 \\
Cert eq of cons / avg cons & 0.9960 & 0.9913 & 0.9807 \\
Search effort & 0.3510 & 0.3853 & 0.4273 \\
1st per prob of job finding & 0.3664 & 0.4094 & 0.5083 \\
2nd per prob of job finding & 0.5650 & 0.6478 & 0.7513 \\
Post-UI prob of job finding & 0.5762 & 0.6566 & 0.7234 \\
$\pi$ & 1.1175 & 1.3608 & 1.8198 \\
q & 1.6225 & 1.2557 & 0.8500 \\
\hline
\end{tabular}

Table 17: Equilibrium under different search parameters

\begin{tabular}{lrrr}
\hline & $Z=0.2, D^{S}=0.1$ & $Z=0.4, D^{S}=0.2$ & $Z=0.8, D=0.2$ \\
Interest rate & 0.01587 & 0.01584 & 0.01587 \\
Unemployment rate & 0.07266 & 0.07647 & 0.07477 \\
Capital / VA & 8.2948 & 8.2838 & 8.2708 \\
Recruitment / VA & 0.0194 & 0.0174 & 0.0166 \\
Wage & 0.7667 & 0.7702 & 0.7709 \\
Value added & 0.9613 & 0.9596 & 0.9618 \\
Std dev of cons & 0.0672 & 0.0693 & 0.0675 \\
Avg U/E cons ratio & 0.9534 & 0.9508 & 0.9636 \\
Cert eq of cons / avg cons & 0.9958 & 0.9960 & 0.9961 \\
Search effort & 0.2349 & 0.3510 & 0.6461 \\
Fraction not searching & 0.1318 & 0.0193 & 0.0172 \\
1st per prob of job finding & 0.3729 & 0.3664 & 0.3017 \\
2nd per prob of job finding & 0.6247 & 0.5650 & 0.6566 \\
Post-UI prob of job finding & 0.6341 & 0.5762 & 0.6612 \\
$\pi$ & 1.2211 & 1.1175 & 1.1028 \\
$\mathrm{q}$ & 1.4597 & 1.6225 & 1.7045 \\
\hline
\end{tabular}




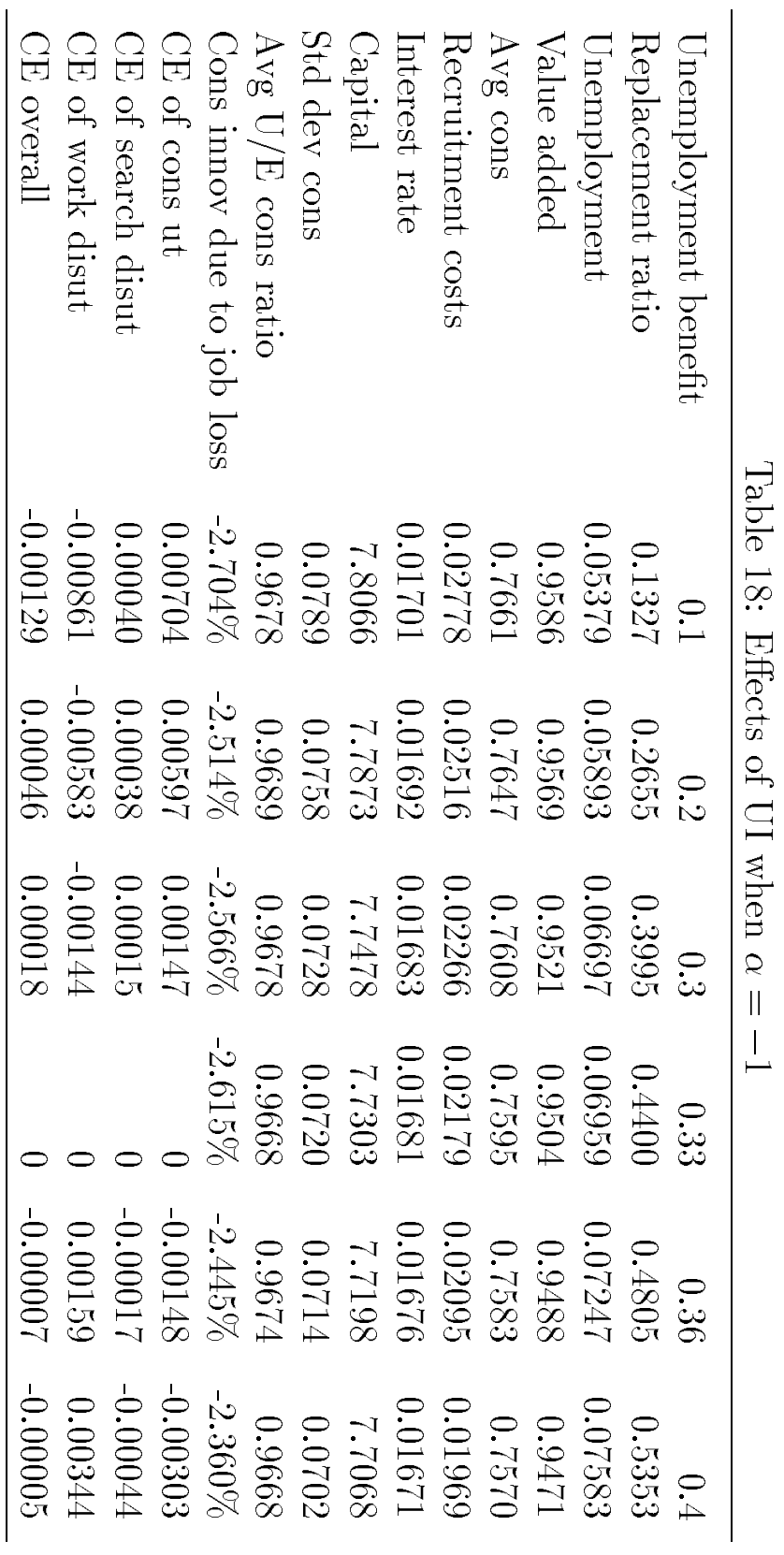




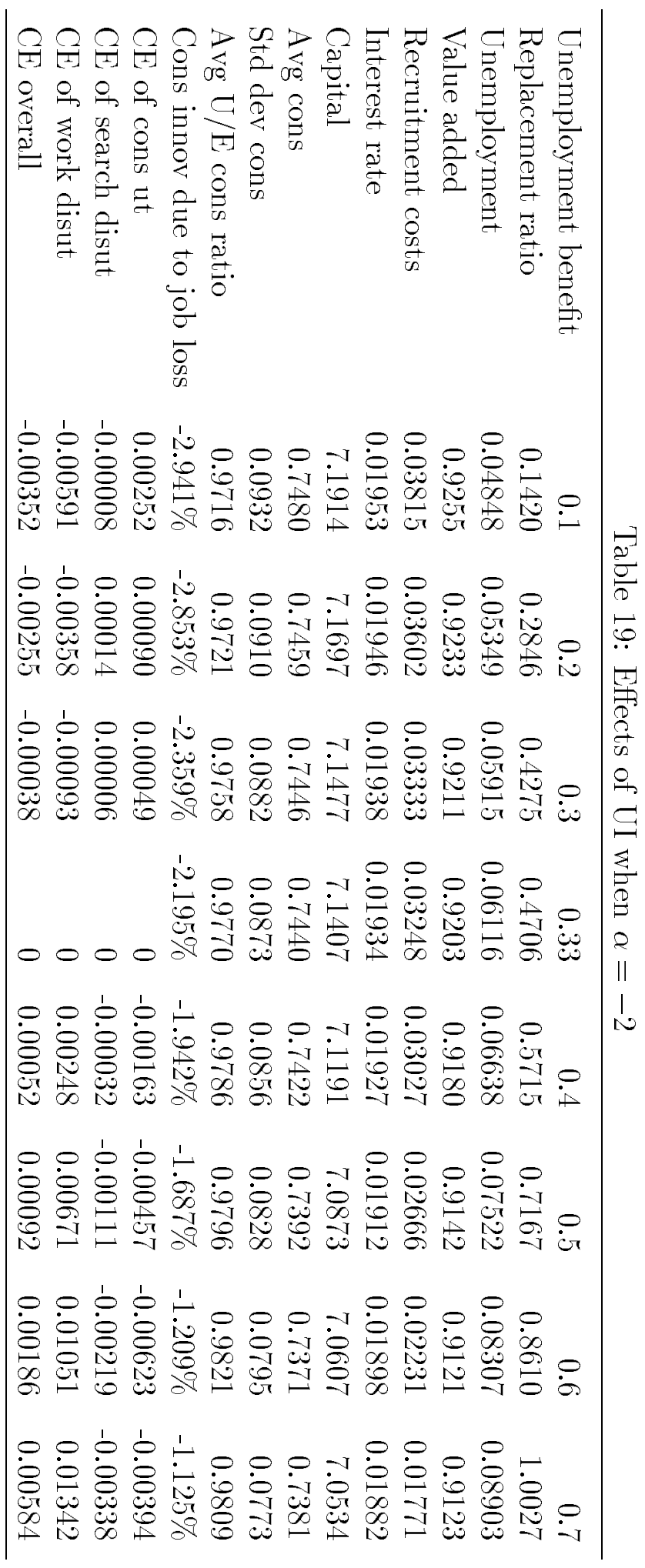




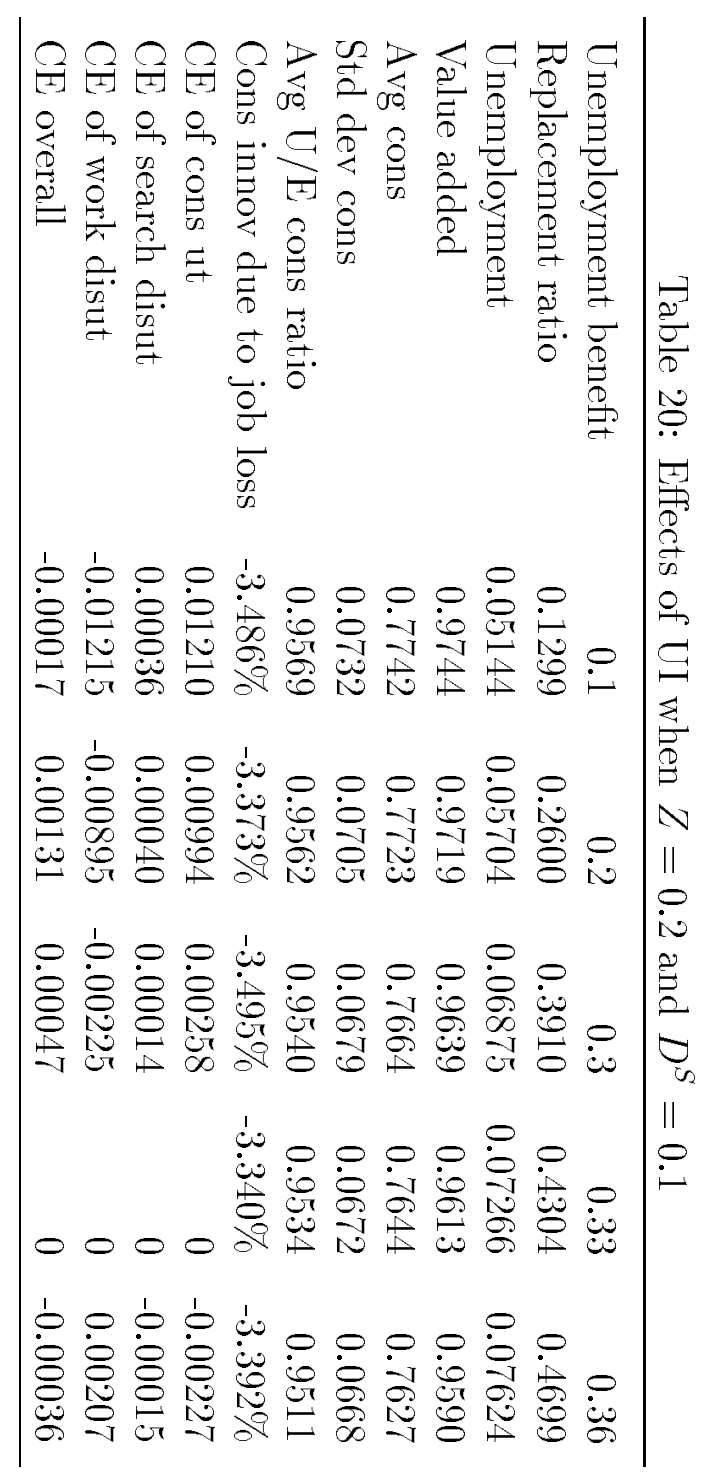




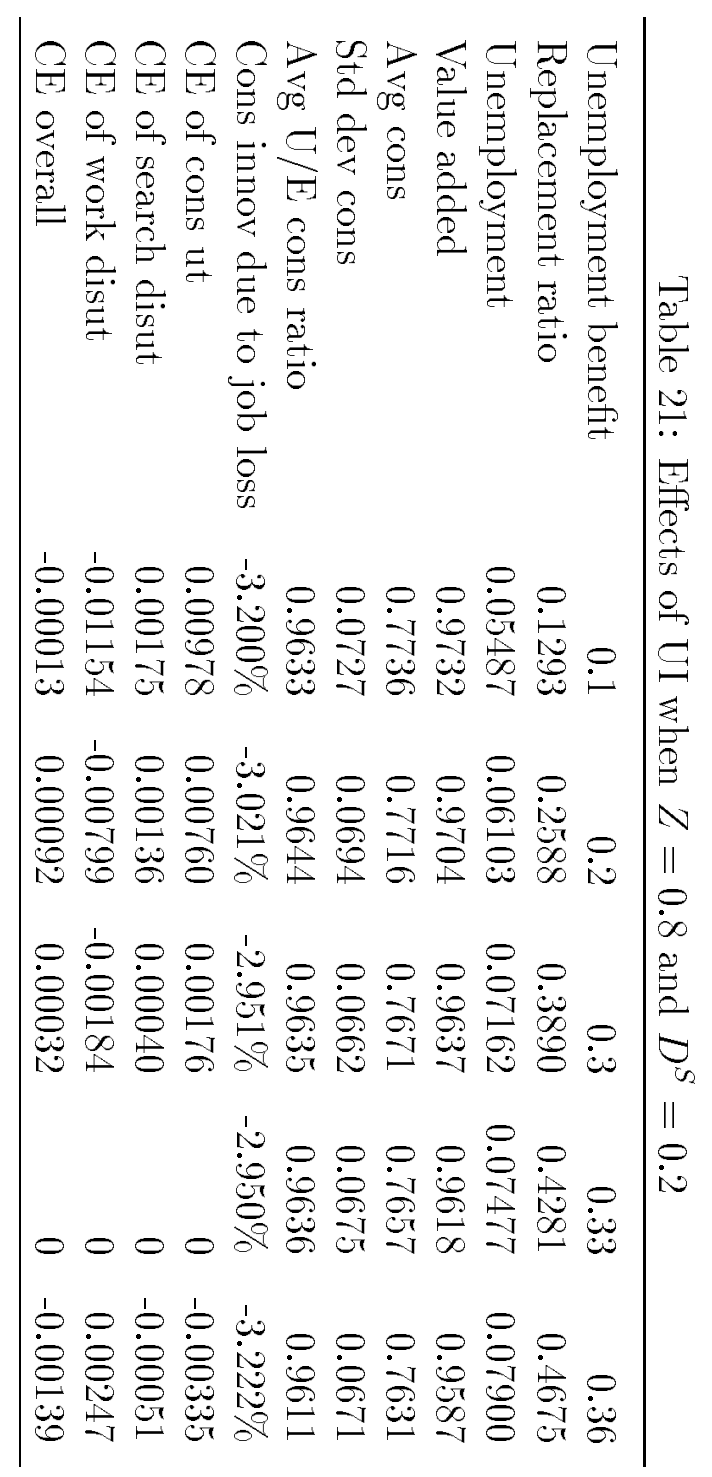

